\title{
Age as a Moderator of Health Outcomes and Trust in Physicians and the Healthcare System
}

\author{
Emma Katz M.S. \\ West Virginia University, eak0007@mix.wvu.edu
}

Follow this and additional works at: https://researchrepository.wvu.edu/etd

Part of the Clinical Psychology Commons

\section{Recommended Citation}

Katz, Emma M.S., "Age as a Moderator of Health Outcomes and Trust in Physicians and the Healthcare System" (2022). Graduate Theses, Dissertations, and Problem Reports. 8331.

https://researchrepository.wvu.edu/etd/8331

This Dissertation is protected by copyright and/or related rights. It has been brought to you by the The Research Repository @ WVU with permission from the rights-holder(s). You are free to use this Dissertation in any way that is permitted by the copyright and related rights legislation that applies to your use. For other uses you must obtain permission from the rights-holder(s) directly, unless additional rights are indicated by a Creative Commons license in the record and/ or on the work itself. This Dissertation has been accepted for inclusion in WVU Graduate Theses, Dissertations, and Problem Reports collection by an authorized administrator of The Research Repository @ WVU.

For more information, please contact researchrepository@mail.wvu.edu. 
Age as a Moderator of Health Outcomes

and Trust in Physicians and the Healthcare System

\author{
Emma Katz, M.S. \\ Dissertation submitted \\ to the Eberly College of Arts and Sciences \\ at West Virginia University \\ in partial fulfillment of the requirements for the degree of \\ Doctor of Philosophy \\ in \\ Psychology \\ Barry Edelstein, Ph.D., Chair \\ Kevin Larkin, Ph.D. \\ Nicholas Turiano, Ph.D. \\ Kristina Hash, Ph.D. \\ Department of Psychology \\ Morgantown, WV \\ 2021
}

Keywords: Trust, health outcomes, age, moderation

Copyright 2021 Emma Katz 


\begin{abstract}
Age as a Moderator of Health Outcomes

and Trust in Physicians and the Healthcare System
\end{abstract}

Emma Katz, M.S.

Trust is an integral part of the healthcare experience. Patient trust is associated with treatment adherence, patient satisfaction, patients engaging in follow-up care, shared decisionmaking, and positive health-related outcomes (e.g., Gupta et al., 2014; Mohseni \& Lindstrom, 2007; Musa et al., 2009; Tam, 2012; Thom, et al., 2004; Trachtenberg et al., 2005). There are several levels of trust discussed in the literature, including interpersonal trust and institutional trust. The current study examined two levels of trust: interpersonal trust in the form of trust in the physician and institutional trust in the form of trust in the healthcare system. The study investigated whether age moderated the relation among these two levels of trust and the selected health outcome variables of self-rated health, patient satisfaction, adherence, patient's preference for decisionmaking, and utilization of doctor's visits, emergency room visits, and hospital admissions. Three hundred ninety-eight English-speaking, community-dwelling adults were recruited to participate in this study via Amazon's Mechanical Turk. Participants were administered self-report measures to assess their level of trust and subjective ratings on health outcome variables. Hierarchical multiple regression analyses were used to examine whether age moderated these relations. Age significantly moderated the relations between trust in physicians and hospital admissions, trust in physicians and patient satisfaction, and trust in the healthcare system and preferred decision making. Findings provided support for the role of age as a moderator of these relations. Future implications of these results are discussed. 


\section{Table of Contents}

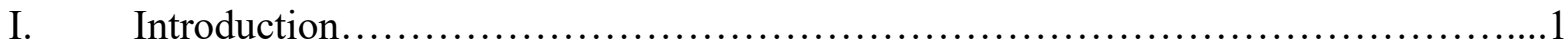

II. Statement of Problem.................................................. 15

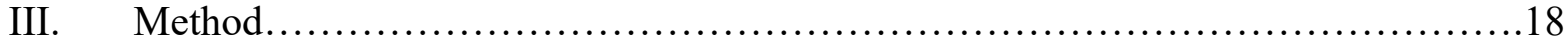

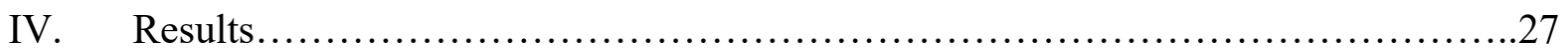

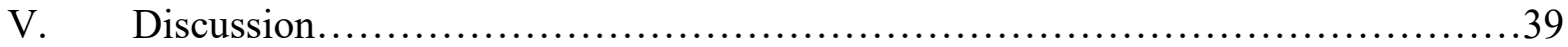

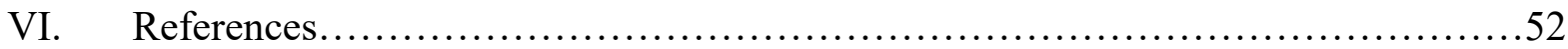

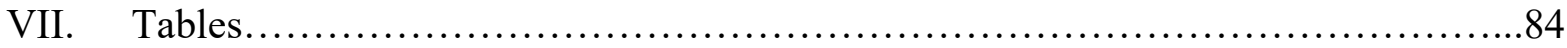

VIII. Figures............................................................... 92

IX. Appendices..........................................................95 
Age as a Moderator of Health Outcomes

and Trust in Physicians and the Healthcare System

\section{The Construct of Trust}

Trust has been variously defined over the years. The following definition by Mayer and colleagues (1995) is consistent with many other definitions in the trust literature. They defined trust as the "willingness of a party to be vulnerable to the actions of another party based on the expectation that the other will perform a particular action important to the trustor" (Mayer et al., 1995, p. 71). The construct of trust also entails an "optimistic acceptance of a vulnerable situation" (Hall et al., 2001). To allow an individual to be optimistic about the future, there needs to be evidence that trust is present, hence why trust has been described as the "glue" that holds communities together (Mechanic, 1996). Trust between any two people necessitates a prediction about future behavior together (Mishra, 1996). Therefore, there is also an element of vulnerability involved in trust, as trust entails risking that the trustee will perform a valued behavior (Mayer et al., 1995) especially since the intentions, motivations, or future actions of the other person or entity are often uncertain (Coulson, 1998; Lewicki \& Bunker, 1996; Ozawa, 2008). Trust also reduces complexity in society (Hardie \& Crichley, 2008) because putting trust in people or systems helps simplify an individual's decision to act (Ward et al., 2011). Within the core concept of trust is the understanding that the individual is trusting based on expectations for the future (Goold et al., 2006). These expectations may be for ensuring advocacy, cooperation, or a good outcome (e.g., a person's health or well-being).

Several levels of trust are addressed in the literature, ranging from interpersonal trust to institutional trust. The following sections will explore both of these levels of trust in greater detail. Improved comprehension of interpersonal trust (trust between people) and institutional 
trust (trust people have in an institution) allows for a better understanding of how trust can develop and grow. Trust-building is often seen as an iterative process, where there is a need for repeated evidence of responsibility, competency, and caring (Borum, 2010; Mechanic, 1996). Thus, through trust, social order can be organized and maintained (Giddens, 1994).

\section{Interpersonal Trust}

Interpersonal trust is trust in another person based on familiarity and previous encounters (Ozawa, 2008). Interpersonal trust is often considered a learned personal trait, built and developed over a period of time and is negotiated between people. An established relationship between trustee and trustor makes it easier for the trustor to rely on the trustee and even anticipate their future actions (Ozawa, 2008). This simplifies interactions and helps maneuver complex exchanges between people (Borum, 2010). Interpersonal trust is positively related to communication between individuals (Greenspan et al., 2000) and rate of reciprocity in interactions, and negatively related to neuroticism (Evans \& Revelle, 2006). Interpersonal trust is also positively related to subjective well-being and life satisfaction (Bjørnskov, 2003).

\section{Trust in Physicians}

Interpersonal trust is an essential component of the medical relationship (O’Malley et al., 2004; Pearson \& Raeke, 2000). While this type of trust encompasses all providers within the medical system, research has focused almost exclusively on trust in physicians (Katz \& Edelstein, manuscript in preparation). The patient can view the physician as an "ally" and, therefore, trust their commitment to his or her well-being (Fuertes et al., 2017). A trusting relationship can help foster a more seamless exchange of information between patient and physician, aid in better problem solving, and encourage shared decision-making (Montori et al., 2006). There is the need for continued high-quality health care, and trust helps facilitate this, as 
patients may use trust as a quality indicator for how they evaluate their medical experiences (Brennan et al., 2013; Calnan \& Rowe, 2008).

There are numerous benefits of a trusting relationship between individuals and physicians. For example, higher levels of trust are associated with greater utilization of healthcare services, higher patient satisfaction with care, and better adherence to provider recommendations (Eveleigh et al., 2012; Gordon et al., 2006; Thom et al., 2004). Patients who trust their physicians are more likely to return for follow-up care appointments (Trachtenberg et al., 2005) and seek treatment sooner (Mollborn et al., 2005). For example, trusting information about cancer screening received from one's doctor is associated with being up-to-date on screening (Ling et al., 2006). Higher patient trust is also associated with reduced difficulty in completing disease-specific tasks for patients with diabetes (Bonds et al., 2004). Patients with higher levels of trust are more willing to disclose sensitive information to a physician and are less likely to want to verify physician's recommendations, reducing the costs associated with getting second opinions (e.g., Berrios-Riveria et al., 2006; Julliard et al., 2008; Thom et al., 2004). Individuals who reported higher trust in their health care professionals had higher healthrelated quality of life and satisfaction with care (Birkhauer et al., 2017) and greater self-efficacy (Lee \& Lin, 2009). Patients with lower levels of trust in the physician reported decreased adherence to treatment recommendations, weak clinical relationships, less satisfaction with their care, lower continuity of care, and lower likelihood of endorsing improvement of their symptoms in the two weeks after their visit (Harju et al., 2006; Musa et al., 2009; Thom et al., 2002). Additionally, lack of trust in providers is significantly associated with patients reporting inadequate provision of necessary medical services during visits with their physicians (Thom et al., 2002). 


\section{Institutional Trust}

The next level of trust, institutional trust, also known as organizational or social trust, refers to trust in a system as a whole. Institutional trust can be influenced by past interactions, the media, and general societal confidence in particular institutions (Ozawa, 2008). As trust is a relational notion (Giddens, 1990), trust with a collective entity like a corporation or a hospital (Zheng et al., 2002) has to be actively produced and retained. At the institutional level, trust is essential for successful cooperation, increased efficiency (Lewis and Weigert 1985; Nooteboom, 2002; Six, 2007), job satisfaction, job performance, and organizational commitment (Dirks \& Ferrin, 2001; Flaherty \& Pappas, 2000; Lewicki et al., 2006). Development of trust in the institution allows for the organization's improved functioning by influencing the quality of the relationship between and among people (Lau \& Cobb, 2010; Tan \& Lim, 2009).

\section{Trust in the Healthcare System}

Institutional trust continues to generate increased interest within the healthcare sector (e.g., Ozawa \& Sripad, 2013; Smith, 2017; Thom et al., 2004). Trust in the healthcare system is a type of institutional trust that focuses on how people trust, interact with and put faith in healthcare institutions and the medical profession (Gilson, 2005). Trust in the healthcare system is developed through the aggregation of positive interactions and experiences over time (Dugan et al., 2005), based on a person's belief in the organization or institution. People who believe the healthcare system will protect their interests are more inclined to want to trust that system (Ozawa, 2008). The reputation of the collective institution is also paramount to the evolution of trust, as individuals wish to trust reputable sources for the protection, stability, and structure they provide (Ozawa, 2008). 
There are many advantages to establishing a trusting relationship between individuals and the healthcare system. Trust generates better medical care, which then increases trust, creating a positive feedback loop (Mollborn et al., 2005). Higher levels of trust in healthcare systems increase the likelihood that patients will adhere to behavioral changes recommended by physicians (Ward et al., 2015) and engage in services (Ozawa et al., 2016). High levels of trust in the healthcare system are also related to better self-reported health status (Mohseni \& Lindstrom, 2007), continuity of care (Ozawa et al., 2016), and increased satisfaction with care received (Hall et al., 2002). From an economic perspective, trust in the healthcare system is also beneficial, as trust increases patient retention and referral rates, which increases revenues (Liesen \& Hyman, 2001). Continued trust in the healthcare system helps alleviate the risk, vulnerability, and uncertainty of medical care when there is a power differential and information asymmetry (Ozawa, 2008) between patients and physicians. Healthcare is a dynamic social institution, so fostering trust between the medical system and the population it serves can strengthen the system itself. With increased social trust in the healthcare institution comes the development of collective social capital, better medical outcomes, and the ability to maintain high demand and utilization of services (Ozawa et al., 2016).

\section{The Relation Between Trust in Physicians and Trust in the Healthcare System}

Trust in physicians and trust in the healthcare system are related to one another, as trust in physicians is an element of trust in the healthcare system. There is reciprocity between both levels of trust, as trust in the healthcare system helps facilitate the formation of trust in the physician, which in turn increases trust in the healthcare system. A patient who has positive interactions with their physician is more likely to report greater trust in the physician, and as the physician is the representative of the healthcare system, this interaction increases trust in the 
healthcare system as well (Ward et al., 2015). Additionally, there are patients who trust their physicians but not the system within which they work, so targeting trust could help focus on these patients as well. The patient needs to believe that the specific healthcare institution is a safe environment for services (Gilson, 2003). Trust in a healthcare system will then influence the likelihood the patient will utilize the services of that healthcare system, the services of a different healthcare system, or any healthcare system at all.

\section{Health Outcome Variables Associated with Trust}

Relations between trust in physicians and healthcare systems, and a variety of health outcome variables have been demonstrated. These outcome variables include higher levels of: treatment adherence (Abel \& Efird, 2013; Trachtenberg et al., 2005), patient satisfaction with care (Lee \& Lin, 2011; Platonova et al., 2008; Thom et al., 2002), self-rated health (Lee \& Lin, 2011; Tam, 2012), patient perception of physician empathy (Hojat, 2007; Hojat et al., 2009), insurer trust (Goold, 2006), medication adherence (Piette et al., 2005), disclosure of sensitive information (Salkend, 2004), greater continuity of care (Mainous et al., 2001), and better utilization of healthcare services (Chamberlain et al., 2014; Glaesmer et al., 2012) and preferred decision-making (Chawla \& Arora, 2013).

The current study focuses on five of these outcome variables in an attempt to explain the relations between trust and these variables. The selected variables include self-rated health, utilization of healthcare services, patient's preference for decision-making, adherence, and patient satisfaction. These variables were selected because of their significance as health outcomes and because there is published research supporting their association with both trust in physicians and trust in the healthcare system (Berrios-Rivera et al. 2006; Bonds et al., 2004; Hall et al., 2002). 


\section{Self-Rated Health}

One important factor associated with trust in physicians and trust in healthcare systems is self-rated health. Self-rated health, also known as self-reported health, self-assessed health, or current health status, refers to a person's subjective comprehension of their own overall health. Self-rated health is one of the most commonly used indexes of well-being (Jylhä, 2009). Selfrated health can be used as a measure of an individual's perception of their health, an indicator of health behaviors, and a tool in health-related behavior modification (Bombak, 2013). It is most often measured in the literature using a single item "How would you rate your health at the present time: Excellent, good, fair, or poor?" (e.g., Graf \& Patrick, 2016; Idler \& Benyamini, 1997; Zajacova \& Dowd, 2011). Self-rated health is associated with outpatient services utilization and Veteran Affairs admissions for health-related problems, with participants who rated their health as "fair" or "poor" being more likely to have higher event rates of service utilization like in-patient hospitalization (DeSalvo et al., 2005). Participants with “poor” selfrated health were four times as likely to be hospitalized (DeSalvo et al., 2005). Self-rated health is also predictive of risk of death within the year subsequent to baseline measurement, with participants who rated their health as "poor" having a mortality rate eight times greater than those who rated their health as "excellent" (DeSalvo et al., 2005).

Association with Trust in Physicians. There is substantial evidence from the trust literature supporting the relation between trust in physicians and self-rated health. Higher levels of trust in one's physician are associated with better health status (Balkrishnan et al., 2003; Freburger et al., 2003; Keating et al., 2004; Tam, 2012; Thom et al., 2002) in healthy samples (Calnan \& Sanford, 2004; Goold et al., 2006; Simon et al., 2014), patients with chronic illnesses (Lee \& Lin, 2004; Piette et al., 2005), and those undergoing medical procedures (Kao et al., 
1998). Longitudinal studies have also found a positive association between trust in physicians and both physical and mental health status (Lee \& Lin, 2011). A meta-analysis of the literature reported a moderate association $(r=0.37)$ between trust in the healthcare professional and health-related status across 47 studies (Birkhauer et al., 2017).

Association with Trust in the Healthcare System. There is also empirical support for the relation between trust in the healthcare system and self-rated health. Higher levels of trust in the healthcare system are also associated with better health status (Armstrong et al., 2006; Berrios-Riviera et al., 2006; Kawachi et al.,1997; Kim et al., 2002; Mohseni \& Lindstrom, 2007). When asked the single item self-rated health question, participants with higher self-rated health status (i.e., excellent or good) report higher scores on the trust measure used than participants with lower self-rated health status (i.e., fair or poor; Kim et al., 2002; Mohseni \& Lindstrom, 2007).

\section{Utilization of Healthcare Services}

Another variable related to trust is utilization of healthcare services. Utilization of healthcare services has been defined as "the use of services by persons for the purpose of preventing and curing health problems, promoting maintenance of health and well-being, or obtaining information about one's health status and prognosis" (Carrasquillo, 2013, p. 2). Utilization occurs when the patient chooses to use health services available to them (Andersen, 2008). The frequency of visits to providers and optimal use of healthcare resources not only helps control more costly services in the future (Balkrishan et al., 2000) but also acts as an indicator about the patient's ability to manage their medical conditions and their current health status (Ritter et al., 2001). Trust is essential in health care utilization of services as it provides increased motivation for patients to seek out care willingly when needed (Hall et al., 2001; Thom 
et al., 2004). The services included in the operationalization of healthcare utilization varies between studies. The services most often assessed include the number of healthcare provider visits, hospitalization, and emergency room visits (Chamberlain et al., 2014; Glaesmer et al., 2012; Lutomski et al., 2013; Short et al., 2005; van Dalen et al., 2014). Other variables include seeking care when needed (LaViest et al., 2009), keeping follow up appointments (LaViest et al., 2009), outpatient office visits (Chamberlain et al., 2014), having a routine check-up within the previous year (Musa et al., 2009), admission to skilled nursing facilities (Chamberlain et al., 2014), and being up-to-date on cancer screenings (Musa et al., 2009; O’Malley, 2004) and vaccinations (O’Malley, 2004).

Association with Trust in Physicians. There is considerable evidence that supports the relation between trust in physicians and the utilization of healthcare services. Trust in one's physician is associated with utilization of hospitalization services (Shenolikar et al., 2004) and preventive health services including cancer screenings across different types of cancer (Gupta et al., 2014; Ling et al., 2006; Musa et al., 2009; O’Malley et al., 2004), vaccinations (Ozawa et al., 2016), and routine check-ups (Musa et al., 2009; O’Malley et al., 2004). Increased utilization of preventative screenings also results in earlier detection of cancer (Gupta et al., 2014; Musa et al., 2009). Lack of trust in physicians is the main reason patients fail to undergo appropriate and timely screening procedures (Fox et al., 2009).

Association with Trust in the Healthcare System. There is also support for the relation between trust in the healthcare system and the utilization of healthcare services. Trust in the healthcare system is associated with utilization of preventive health services including cancer screening and check-ups (Musa et al., 2009). Trust in the healthcare system is also a significant predictor for utilization of hospital healthcare services (Jang et al., 2005). In addition, trust in 
healthcare systems is associated with utilization of health services, including keeping follow-up appointments, seeking and getting needed care, taking medical advice, and filling prescriptions (LaViest et al., 2009).

\section{Preference for Decision-making}

A variable associated with both levels of trust is patient's preferences for decisionmaking, or one's desired role in the decision-making process when making decisions about medical care. Patient-centered care is an approach to medical care that encourages medical providers to respond to their patient's preferences on how involved they want to be in making treatment decisions (Deber et al., 2007; Lee \& Emanuel, 2013). Patients may prefer decisions to be made passively, autonomously, or jointly, shared with their provider. Shared decision-making is the process of making healthcare decisions through collaboration between the physician and patient (Stacey et al., 2014). Shared decision-making is not necessarily the middle point between autonomous and passive decision-making, as the level of involvement of decision-making is instead often viewed on a continuum, where individuals can choose how involved they would like to be. Shared decision-making is beneficial for patients, as it contributes to more informed choices and supports patient autonomy (Elywyn, 2012; Lee \& Emanuel, 2013). Empirical evidence is still somewhat inconclusive, though, in terms of what level of participation of decision-making patients prefer (e.g., Chewning et al., 2012; Schattner et al., 2006), as preferences for participation does seem to vary depending on patient characteristics. For example, older adults seem to prefer more passive decision-making roles (Arora \& McHorney, 2000; Balkrishnan et al., 2003). Recent meta-analysis found that patients tend to prioritize shared decision-making (e.g., Chewning et al., 2012). The most significant predictor of a patient's 
preferred role in medical decision-making is their level of trust in physicians (Kraetschmer et al., 2004; Trachtenberg et al., 2005).

Association with Trust in Physicians. There is support in the literature for the relation between patient-physician trust and a patient's preferred role in decision-making. Patients with higher levels of trust in their physicians desire less autonomy over decision-making and prefer a more passive role in the decision-making process during visits than patients with lower levels of trust (Arora \& McHorney, 2000; Balkrishnan et al., 2003; Chawla \& Arora, 2013; Kraetschmer et al., 2004). Higher trust in physicians is also associated with patients feeling well informed about decision-making procedures involving medication decisions, cancer screening decisions, and surgery decisions (Sepucha et al., 2010). There may be a downside to trust, however, as patients who trust their physicians desire less input in the decision making process (Arora \& McHorney, 2000). This could cause patients to accept a physician's treatment suggestions as indisputable or as the only option instead of conversing about additional options if the physician and patient have different values that could influence decision-making.

Association with Trust in the Healthcare System. There is support for the relation between trust in the healthcare system and patients' preferences for decision-making as well. Patients' preferred involvement in medical care is significantly associated with trust in the medical profession (Ommen et al., 2011; Trachtenberg et al., 2005). Higher levels of trust in the healthcare system are also associated with a more deferential patient role in medical decisionmaking (Trachtenberg et al., 2005). That is, patients who trust the healthcare system are more likely to choose a passive role in the decision-making process, most likely because they trust that decisions will be made in their best interest (Trachtenberg et al., 2005).

\section{Adherence to Medical Regimens}


Adherence to medical regimens is associated with trust in physicians and trust in the healthcare system (e.g., Cuffee et al., 2013; Lee \& Lin, 2009; O’Malley et al., 2004). Adherence refers to the "extent to which the person's behavior corresponds with agreed upon recommendations from a healthcare provider" (Burkhart \& Sabate, 2003, p. 7). This can include taking prescribed medication, following treatment protocols, and the overall extent to which a patient follows their doctor's advice (Jimmy \& Jose, 2011). Individuals who report higher rates of adherence engage in better self-management of illnesses, improved lifestyle changes, and better health outcomes (Brown \& Bussell, 2011; Conn et al., 2016; Martin et al., 2005).

Adherence to Medical Regimens and Trust in Physicians. Trust in physicians is associated with adherence to physician advice and treatment regimens (Lee \& Lin, 2009; Polinski et al., 2014; Thom et al., 2002). Patient trust in physicians is one of the strongest correlates of adherence to medical recommendations and treatment (O’Malley et al., 2004; Safran et al., 1998; Salkend et al., 2004). Trust in physicians is positively associated with increased likelihood of adherence to treatment (e.g., Abel \& Efird, 2013; Lee \& Lin, 2009; Musa et al., 2009; Polinski et al., 2014). Patients with higher levels of trust were more likely to report following their physician's recommendations and taking their prescribed medication than patients with lower levels of trust (Graham et al., 2015; Thom et al., 2002).

Adherence to Medical Regimens and Trust in the Healthcare System. Trust in the healthcare system is related to adherence to medical regimens. Patient who report higher levels of trust in the healthcare system are more likely to adhere to medical advice, follow treatment recommendations, and take their prescribed medication (Cuffee et al., 2013; Traylor et al., 2010). Trust in the healthcare system was negatively associated with medication non-adherence (Dale et 
al., 2016; LaViest et al., 2009; Wamala et al., 2007) and a lack of adherence to preventive cancer screenings (Adams et al., 2017; Palmer et al., 2008).

\section{Patient Satisfaction}

A final variable related to trust is patient satisfaction. Patient satisfaction refers to the “patient's perception of care received compared with the care expected” (Eng et al., 2006). Satisfaction with health care is an important aspect of assessing quality healthcare (Alasad et al., 2015; El-Nagger et al., 2013). Patients with higher levels of satisfaction in medical settings are more likely to adhere to physician recommendations (Zolnierek \& Dimatteo, 2009), recommend the healthcare system to others (Jenkinson et al., 2002), and have greater continuity of care (Nutting et al., 2003). Trust is strongly associated with patient satisfaction (Chen et al., 2020; Fan et al., 2005; Lee \& Lin, 2011).

Association with Trust in Physicians. There is empirical support for the relation between trust in physicians and patient satisfaction. Patients with higher levels of trust in their physicians reported increased patient satisfaction (Chen et al., 2020; Krot \& Rudawska, 2017; Lee \& Lin, 2011; Platonova et al., 2008; Weng, 2008). In a study of 7,204 participants, trust was reported as the variable most strongly associated with patients' satisfaction with their physician (Safran et al., 1998). A meta-analysis examining whether patients' trust in the health care professional was associated with health outcomes reported a moderate association $(r=0.57)$ between trust and patient satisfaction across 15 studies (Birkhauer et al., 2017). Patients with low levels of trust reported being less satisfied with their care and less likely to follow their doctor's advice (Thom et al., 2002).

Association with Trust in the Healthcare System. There is support in the literature for the relation between trust in healthcare and patient satisfaction. Patients with higher levels of 
trust in healthcare reported higher levels of patient satisfaction with care (Balkrishnan et al., 2003; Egede \& Ellis, 2008; Hall et al., 2002; Tang, 2011). Low levels of trust in the medical profession and healthcare system were also associated with a lack of patient satisfaction with health care (Egede \& Ellis, 2008; Shan et al., 2016).

\section{Age and Association with Trust and Health Outcome Variables}

Age was chosen as a potential moderator in part because of the interrelations among age, trust in physicians and the healthcare system, and important health outcome variables. Age is significantly related to both trust in physicians (e.g., Arora \& McHorney, 2000; Bachinger et al., 2009; Kraetschmer et al., 2004; Rodriguez et al., 2013) and trust in the healthcare system (e.g., Balkrishnan et al., 2003; Benjamins, 2006; Boulware et al., 2003; Hall et al., 2002), with older adults reporting higher healthcare-related trust levels than young adults (e.g., Mainous et al., 2001; Simon et al., 2014). This could be due to older adults' increased interactions with health care providers because of multiple chronic or comorbid health conditions (Bell et al., 2013) or cohort differences in trust (Bell et al., 2013); or perhaps with older age comes more time to establish a trusting relationship with their physicians. Trust in physicians and the healthcare system also increases across the lifespan (Li \& Fung, 2013; Poulin \& Haase, 2015), which could contribute to higher rates of trust among older adults in medical settings.

While age is related to levels of trust (e.g., Poulin \& Haase, 2015), age is also related to health outcome variables, including utilization of healthcare services (Institute of Medicine, 2008), decision-making (Chi et al., 2017; Best \& Charness, 2015), patient satisfaction (Peck, 2011), adherence (Jin, 2016), and self-rated health (Amstadter et al., 2010). For example, Chawla and Arora (2013) and Naik et al. (2011) examined age-related differences in patient preferences 
for involvement in medical decision-making and determined that older adults are more likely to prefer passive roles in decision-making than younger adults.

In summation, research has linked trust to the health outcome variables (e.g., Lee \& Lin, 2011, Tam, 20212), age to the health outcome variables (e.g., Chi et al., 2017; Rodriguez et al., 2013; Simon et al., 2014), and age to trust (e.g., Hall et al., 2002; Rodriguez et al., 2013). However, there is a lack of research exploring how all these variables are connected. It is important to continue examining the role age plays in the trusting relationship and how age may act as a moderator in furthering our understanding of the trust in physicians and trust in the healthcare system literature. While there is increasing evidence of age-related differences in trust and age-related differences in associated health outcome variables, no study has yet explored the role age may play as a moderator among self-rated health, utilization of healthcare services, patient preference for decision-making, adherence, and patient satisfaction, and either trust in the healthcare system or trust in physicians.

\section{Statement of the Problem}

Trust in healthcare is foundational for patient-centric, effective treatment. With increased trust comes the increased likelihood of patients engaging in follow-up care, treatment adherence, shared decision-making, increased patient satisfaction, and positive health-related outcomes (e.g., Gupta et al., 2014; Mohseni \& Lindstrom, 2007; Musa et al., 2009; Tam, 2012; Thom et al., 2004; Trachtenberg et al., 2005). Trust acts as a barometer for how patients evaluate their interactions with medical professionals and their overall healthcare experience. Measuring trust allows for a way to understand how to maintain and even strengthen individuals' healthcare engagement and inform intervention efforts to increase trust. Promoting health through enhancing patient trust has implications for improving healthcare utilization in medical services 
and helping reduce health disparities, as increased trust is associated with increased utilization of healthcare services (e.g., Hall et al., 2001; Thom et al., 2004).

There are several levels of trust discussed in the literature, including interpersonal trust and institutional trust. Interpersonal trust, trust between people, helps maneuver complex relationships between people (Borum, 2010) and makes it easier for the trustor to rely on the trustee in various interactions (Ozawa, 2008). Trust in physicians is a type of interpersonal trust. Trust in physicians is positively associated with many beneficial health outcomes, including better utilization of healthcare services, higher patient satisfaction with care, better follow-up care, and better adherence to provider recommendations (e.g., Eveleigh et al., 2012; Gordon et al., 2006; Thom et al., 2004).

Institutional trust, trust people have in the institution, facilitates social exchange (e.g., Frazier et al., 2013) and improves the quality of the relationship between people within the overall system (Lau \& Cobb, 2010; Tan \& Lim, 2009). Trust in the healthcare system is a type of institutional trust. Trust in the healthcare system is positively associated with various health outcomes including better continuity of care, increased continuity of care, better self-reported health status, and increased satisfaction by patients with care received (e.g., Hall et al., 2002; Mohseni \& Lindstrom, 2007; Ozawa et al., 2016).

The trust literature has established various relations between health outcome variables and these two levels of trust, trust in physicians and healthcare systems. Outcome variables with empirical literature supporting their association with trust include treatment adherence (Thom et al., 2004; Trachtenberg, Dugan, \& Hall, 2005), medication adherence (Piette et al., 2005), selfrated health (Balkrishnan et al., 2003; Berrios-Riviera et al., 2006), utilization of healthcare 
services (Musa et al., 2009), insurer trust (Kao et al., 1998), continuity of care (Mainous et al., 2001), and preference for shared decision-making (Trachtenberg et al., Kraetschmer et al., 2004).

While the foregoing relations have been established, there has been no attempt in the trust literature to examine factors that account for the strengths of relations of these variables and trust in physicians or trust in the healthcare system. Age is a variable with the potential to influence the strength of these relations. Age is significantly related to both trust in physicians and trust in the healthcare system (e.g., Arora \& McHorney, 2000; Bachinger et al., 2009; Balkrishnan et al., 2003; Benjamins, 2006; Boulware et al., 2003; Hall et al., 2002; Kraetschmer et al., 2004;

Rodriguez et al., 2013). Additionally, with an increasingly aging population (U.S. Census Bureau, 2017), and the age-related increase in contact between individuals and the healthcare system, it is important to consider the role of age in healthcare trust.

There is a consensus in the field that trust in physicians and in the healthcare system is associated with beneficial health outcomes, and that age influences the level of trust. There is no published research that has addressed the potential role of age in moderating the relation between trust and important healthcare outcome variables.

The current study sought to determine whether age moderates the relation between these two levels of trust and five health outcome variables. Health outcome variables included selfrated health, utilization of healthcare services, patient's preference for decision-making, adherence, and patient satisfaction. These variables were chosen due to their significance as health outcomes and because there is empirical literature that supports their association with both trust in physicians and trust in the healthcare system.

\section{Research Questions}

1. Does age moderate the relation between trust in physicians and self-rated health? 
2. Does age moderate the relation between trust in the healthcare system and self-rated health?

3. Does age moderate the relation between trust in physicians and utilization of healthcare services?

4. Does age moderate the relation between trust in the healthcare system and utilization of healthcare services?

5. Does age moderate the relation between trust in physicians and preferred decisionmaking?

6. Does age moderate the relation between trust in the healthcare system and preferred decision-making?

7. Does age moderate the relation between trust in physicians and adherence?

8. Does age moderate the relation between trust in the healthcare system and adherence?

9. Does age moderate the relation between trust in physicians and patient satisfaction?

10. Does age moderate the relation between trust in the healthcare system and patient satisfaction?

\section{Method}

\section{Participants}

Participants in this study were recruited through Amazon's Mechanical Turk (MTurk), an online marketplace for the coordination of workers to complete tasks. The use of MTurk enabled recruitment of a diverse population of young, middle-aged, and older adults from various geographic regions, and facilitates data collection. Using MTurk, researchers can recruit participants based on specific characteristics such as age, geographic location, and gender. Researchers can also determine the acceptable parameters for a participant's Human Intelligence 
Tasks (HIT) success rate, which is the individual's average success rate for attention check questions completed in past surveys through the site. MTurk has been used in previous studies to collect survey and questionnaire data for behavioral research (Buhrmester et al., 2011; Mason \& Suri, 2012; Paolacci \& Chandler, 2014). The MTurk sample in America is comparable to nationally representative survey sample populations in terms of age, race/ethnicity, gender ratios, education levels, and success rates of attention check items (Berinsky, et al., 2012). Additionally, MTurk participants have been shown to respond truthfully across items completed and similarly in terms of attention and consistency compared to samples recruited through other methods (Paolacci \& Chandler, 2014).

Power analyses using G*Power 3.1.9 (Faul et al., 2013) were conducted to determine the sample size required for the multiple regression analyses used for the current study. The sample size was determined for an estimated small-moderate effect size $(d=.30)$ with 7 criterion variables and intended power of .80. This effect size was based on a recent systematic review (Birkhauer et al., 2017) examining the influence of trust in the healthcare professional on health outcome variables, in which a small-moderate effect size was reported across studies. Results of this power analysis suggested a target sample size of 240 total participants. With the inclusion of covariates in this study, the target sample size was 302 . The final sample of 398 participants was then well powered for the moderation tests that were used.

One hundred fifty participants were recruited for each of three age groups: young adults (18-40 years old), middle-aged adults (40-65 years old), and older adults (65 years old and older; Fingerman et al., 2011). All recruited participants were from the United States. Participants under 18 years of age were excluded from this study. Study participants were reimbursed $\$ 1.00$ 
for participation. Of the initially collected 450 participants, 52 were excluded from further analyses. The final sample included 398 participants

\section{Study Design and Procedures}

Data were gathered via MTurk in December 2020. The survey-based methodology has been used in similar studies assessing trust in healthcare settings (Birkhauer et al., 2017; Musa et al., 2009). The present study employed a correlational design.

To obtain an equal number of participants in each age group, participants were recruited through MTurk in small groups within the following age ranges: 4 young adult groups (ages 1824, 25-30, 31-35, 36-40), 5 middle-age adult groups (ages 41-45, 46-50, 51-55, 56-60, 61-64), and 3 older adult groups (ages 65-69, 70-74, and 75 and older, which is the oldest age group MTurk allows to be recruited). This helped with recruiting an even number of older adult participants, as research conducted online with older adults can often result in a large sample base that would be considered "young older adults" (i.e., 65 to 69 years old; Guatam et al., 2019).

Participants responded to a description of the study advertised on MTurk. Interested participants were directed to a set of questionnaires and assessment measures on Qualtrics, which was the hosting site for the survey. When participants chose to complete the survey online, they were presented first with a cover letter discussing the study, description of the procedures, discomforts, benefits, financial considerations, confidentiality, and informed consent. After consenting, participants were then asked their birth year, which was used to screen for individuals across age groups. If an individual was not the necessary age for participation in the survey, or if enough participants from that age bracket have already been recruited, they were not permitted to complete the rest of the survey. Next, participants were asked if they had seen a 
physician at least twice during the past 2 years. Hall and colleagues (2001) used the same prompt with the Wake Forest Trust in Physicians Scale. The 2-year time frame also included preCOVID-19 doctors' appointments. If participants answered "no" to this question, they were not permitted to complete the rest of the survey.

After completing the demographic questionnaire, all participants completed the online survey consisting of self-report measures for each of the variables. The order in which participants completed these measures was randomized to help control for order effects. At the end of the survey, participants were asked for their age in years. This allowed the researcher to check for valid age reporting across the study during data cleaning by sifting out any invalid data due to misrepresentation of age. Additionally, to increase the likelihood of including individuals with high-quality data, validity checks were included within each self-report measure administered (e.g., For this item, please respond with "Strongly agree"). There was one validity check per measure. Validity checks increase the accuracy of self-report data and help to decrease inattentive or careless responding (Oppenheimer et al., 2009). Data for participants whose dates and age did not match were excluded from analyses $(n=37)$. Participant responses reflecting more than one incorrect validity check item resulted in exclusion from the final sample $(n=15)$. Of the participants excluded from further analyses, 18 were young adults, 23 were middle-age adults, and 11 were older adults.

\section{Measures}

\section{Demographics Questionnaire}

A demographic questionnaire was used to assess a variety of individual characteristics. The questionnaire included questions regarding age, sex, race/ethnicity, highest education 
attained, marital status, occupational status, COVID-19 diagnosis, and year born. For a copy, see Appendix A.

\section{Trust in the Physician}

The Wake Forest Trust in Physicians Scale (WFTPS; Hall et al., 2002) assessed the degree to which participants trust their physicians (e.g., "Your doctor will do whatever it takes to get you all the care you need.”). The WFPTS is a 10-item assessment instrument that uses a 5point Likert response scale with response choices ranging from 1 (Strongly Disagree) to 5 (Strongly Agree). Responses were summed, with total scores ranging from 10 to 50. Higher scores indicate higher levels of trust. Initial examination included 959 participants in the general population and a regional (North Carolina) survey of 1,199 Health Maintenance Organization members. The measure demonstrates strong internal consistency coefficients $(\alpha=0.79-0.93$; Hall et al., 2002; Katz \& Edelstein, under review) among nationally represented communitydwelling samples. Two-month test-retest reliability in the initial validation study was adequate ( $\alpha=0.75$; Hall et al., 2001). Convergent validity evidence was demonstrated with the WFPTS through positive relations with assessment measures of trustworthiness, satisfaction with care, patient-perceived physician's empathy, and insurer trust (Hall et al., 2001; Katz \& Edelstein, under review). The internal consistency estimate was strong for the current sample, $\alpha=.81$. For a copy of the scale, refer to Appendix B.

\section{Trust in the Healthcare System}

The extent to which participants trust the healthcare system was assessed through the Health Care System Trust Scale (HCSTS). The HCSTS was the reverse-coded version of the published Revised Health Care System Distrust Scale (Shae et al., 2008). Shae and colleagues developed this scale to examine participants distrust in the healthcare system. Initial assessment 
of 255 medical patients demonstrated strong internal consistency reliability $(\alpha=0.83$; Shea et al., 2008). Evidence for convergent validity of the scale is based on positive relations with measures of trust in one's physician, a global item assessing general social trust, and a global item of trust in the health care system (Shea et al., 2008). For the purpose of this study, the distrust scale (Shea et al., 2008) became a trust scale with the reversal of scoring. Our reversecoded, 9-item, self-report measure used a Likert scale ranging from 1 (Strongly Disagree) to 5 (Strongly Agree). Respondents rated the extent to which they trust the healthcare system in general. While the current reliability evidence provided by Shae and colleagues is sufficient regardless of how the instrument is scored (2008), internal consistency reliability was strong among the current sample, $\alpha=.80$.

Reverse-scoring calls into question the validity evidence gathered with the original scoring system. Thus, validity evidence for this measure was gathered during this study. Evidence for convergent validity of the scale is based on positive, significant relations between total scores on the HCSTS and scores on the WFPTS $(r=.380), \operatorname{PDSM}(\mathrm{r}=.460)$, and HCSQ $(r=.257)$, and negative, significant relations with healthcare utilization for doctors' visits $(r=-.319)$, emergency room visits $(r=-.402)$ and number of hospital admissions $(r=-.354)$. This is consistent with prior validity evidence reported for measures of trust and conceptuallyrelated constructs of patient satisfaction, healthcare utilization, and preferred decision-making (e.g., Birkhauer et al., 2017; Hall et al., 2002; Jang et al., 2005). Discriminant validity evidence was also demonstrated based on non-significant, weak relations with education level $(r=.057)$, gender $(r=-.096)$ and marital status $(r=.040)$. These relations were expected in light of previous research about the relations between trust and these demographic variables (e.g., Egede \& Ellis, 2008; Tsai et al., 2018). For a copy of the measure, refer to Appendix C. 


\section{Self-Rated Health}

The Patient-Reported Outcomes Measurement Information System 10 Global Health Scale (PROMIS10; Hays et al., 2009) was administered to assess self-rated health. A single Likert item, "How would you rate your health at the present time?," is most commonly used to assess self-rated health in the literature (Graf \& Patrick, 2016; Zajacova \& Dowd, 2011). The PROMIS10 incorporates this item in addition to assessing other domains of global health from a multidimensional perspective. The PROMIS 10 Global Health Scale is a 10-item assessment instrument that uses a 5-point Likert response scale for scoring. The measure assesses five domains of global health: physical function, fatigue, pain, emotional distress, and social health. Response choices change depending on the question asked, to best assess the construct of global health and so that none of the items are reverse-coded (Hayes et al., 2010). For items 1 to 6, response choices range from 1 (Poor) to 5 (Excellent). For item 7, response choices range from 1 (Not at all) to 5 (Completely). For item 8, response choices range from 1 (Always) to 5 (Never). For items 9 and 10, response choices range from 1 (Very Severe) to 5 (None). All 10 questions were summed together for an overall global health score, with higher scores indicating better self-rated health status. Initial assessment of 21,133 participants demonstrated strong internal consistency reliability ( $\alpha=.86$; Hays et al., 2009). Evidence for convergent validity is based on positive relations with measures of health quality of life, pain, and other measures of self-rated health (Hays et al., 2009; Lam \& Kwa, 2018). Test-retest reliability with a sample of 204 participants with Lupus was 0.89 after 1 week (Kasturi et al., 2018) and 0.86 with 1102 stroke participants after 2 follow-up appointments (on average 6 months; Katzan \& Lapin, 2017). Internal consistency for the current sample was strong, $\alpha=.83$. For a copy of the measure, refer to Appendix D. 


\section{Utilization of Healthcare Services}

Three measures were administered to assess the utilization of healthcare services. Each measure consists of a single-item statement that targets a different component of healthcare utilization; outpatient visits, hospitalization, and emergency room visits (e.g., "Please recall the total number of doctors' visits you have had within the last year"; Short et al., 2010). Selfreported utilization of healthcare services is often used as a proxy when administrative data or medical claims are not available (Short et al., 2010). All respondents used a continuous scale to indicate the frequency of their visits over the previous twelve months. The items were not summed for a total score, since they were assessing different constructs. Each item was treated like a separate measure, with the score on each entered separately during data analysis. Item selection was determined by the empirical literature and based on the most commonly assessed services for utilization of healthcare (Chamberlain et al., 2014; Glaesmer et al., 2012; Lutomski et al., 2013; Ritter et al., 2001; Short et al., 2005; van Dalen et al., 2014). In a sample of 790 community-dwelling adults, higher levels of hospitalization and emergency room visits within the last year were predictive of increased mortality (van Dalen et al, 2014). Healthcare provider visits, hospitalization, and emergency room visits were also all predictive of self-rated health (Chamberlain et al., 2014; Lutomski et al., 2013). Each measure was examined separately to assess the role utilization of that specific healthcare services had on patients' trust in their physicians and healthcare system. In a study of 4,812 participants, percent agreement between self-reports and administrative claims was assessed for each measure, with $91.6 \%$ perfect agreement for yearly emergency room visits, $93.2 \%$ for yearly inpatient admissions, and $74.8 \%$ for yearly doctors' visits (Short et al., 2010). For a copy of the measures, refer to Appendix E.

\section{Preference for Decision-Making}


The Problem-Solving Decision-Making Scale (PSDM; Deber et al., 1996) assessed the degree to which participants prefer to be involved in different decision-making scenarios through the use of vignettes. The three clinical vignettes represent different types of decisions termed morbidity, mortality, and quality of life by the authors. Using the vignettes, participants are queried to hypothetically consider their participation preferences regarding diagnosis, treatment options, risks and benefits, probabilities of how likely the risks and benefits are to occur, how acceptable those risks and benefits are for the participant, and what is ultimately chosen for possible treatment. Participants answer the hypothetical question, "Who should make the decision?", by choosing one of the following: "the doctor alone" (1), "mostly the doctor" (2), "the doctor and you equally" (3), "mostly you" (4), or "you alone" (5), to the question "Who should make the decision?". To determine preferred role, mean scores are computed and then collapsed into 1 of 3 classifications: passive (mean score less than 3), shared (mean score between 3 and 3.99), or autonomous (mean score greater than or equal to 4; Deber et al., 1996; Deber et al., 2007). Higher scores indicate a higher desire for autonomy in medical decisions. Initial reliability estimation using 300 medical patients yielded a Cronbach's alpha coefficient of 0.90 and test-retest reliability after a month was 0.57 . Estimation of internal consistency reliability in a sample of 606 hospitalized patients revealed a Cronbach's alpha of 0.87 (Kraetschmer et al., 2004). Reliability estimation with a sample of 401 community-dwelling adults resulted in a Cronbach's alpha of 0.93 (Gregório et al., 2020). Internal consistency reliability for the current sample was strong, $\alpha=.94$. For a copy of the measure, refer to Appendix F.

\section{Adherence}


A single-item was used to measure adherence in this study: "How often do you follow what your physician prescribes for you?’. This 1-item, self-report measure used a Likert-type scale with response choices ranging from 1 (Never) to 5 (Always) to have respondents rate the extent which they adhere to their physician's recommendations. For a copy of the measure, refer to Appendix G.

\section{Satisfaction}

The Health Care Satisfaction Questionnaire (HCSQ; Gagnon et al., 2006) was developed to examine patients' satisfaction with the healthcare services and the system as a whole. The HCSQ is a 23-item measure that uses a Likert-type scale ranging from 1 (Not at all) to 4 (Extremely). Responses are summed with higher scores indicating higher levels of satisfaction. Initial assessment of 873 participants demonstrated strong internal consistency reliability $(\alpha=$ .92; Gagnon et al., 2006). Test-retest reliability with a sample of 38 participants was 0.72 after an average of 16 days (Gagnon et al., 2006). Evidence for convergent validity was based on positive relations between observed and latent variables within the measure (Gagnon et al., 2006), where intraconstruct correlations were greater than 0.5 for convergent validity criterion to be fulfilled (Livolsi \& Meschi, 2002). Internal consistency reliability for the current sample was strong, $\alpha=$ 91. For a copy of the measure, refer to Appendix H.

\section{Results}

\section{Data Management and Preliminary Analyses}

All statistical analyses were conducted with the Statistical Package for the Social Sciences (SPSS 21). Prior to analyses, the variables utilized were examined for accuracy of data entry and validity checks were conducted. Data were screened for missingness. Preliminary analyses evaluated primary variables (e.g., total score on the WFPTS) for missingness and 
frequencies revealed no variable had $5 \%$ or more of data missing. However, the analysis also revealed that the HCSTS, HCSQ, and PDSM measures had some missingness (less than 5\%). Subsequently, Expectation Maximization was used with these variables as it does not increase central tendency or reduce the variance (Field, 2013). There were no significant changes observed in the mean or standard deviations of the variables after undertaking Expectation Maximization on the data. Little's Missing Completely at Random test was also conducted to assess for patterns of missingness and was not significant $(p=.961)$. Therefore, data were assumed to be missing completely at random.

Preliminary analyses were then conducted to assess for any problems with multicollinearity, homoesdasticity, and normality. Variables were examined for normality by analyzing the skewness, kurtosis, and the presence of any outliers. Normality of data was confirmed, as skewness and kurtosis values were within acceptable limits (i.e., between -2 and +2 ; George \& Mallery, 2010). Univariate outliers were checked by examining Z-scores. Scatterplots of variables of interest and correlation tables were inspected for bivariate outliers. Multivariate outliers were checked as well through the Mahalanobis distance test. The variance inflation factor and tolerance levels were also examined for multicollinearity (Field, 2013). There were no problems regarding multicollinearity, homoesdasticity, normality, or outliers.

\section{Descriptive Statistics}

Participant characteristics

Descriptive statistics (mean, standard deviation) were computed to describe the sample, and distributions were plotted for each variable. Participant age ranged from 19-81 years $(M=$ $52.43, S D=17.18)$, and the sample reported an average of 13.88 years of education $(S D=5.54)$. Almost a quarter of participants had been diagnosed with COVID-19, and most reported at least 
one chronic health condition. The majority of participants also identified as male, married, and White/Caucasian (see Table 1).

\section{Correlations}

Pearson's correlation coefficients were calculated for all dependent measures including self-rated health, utilization of healthcare services, preference for decision-making, adherence, and patient satisfaction. Associations among these variables were reported in a correlation matrix in Table 2. Means, standard deviations, and ranges for scores of each measure used in this study appear in Table 3. One interesting finding outside of the purview of the dissertation topic was the relation between COVID-19 status and predictor and criterion variables, which will be discussed later in the document.

\section{Statistical Analyses}

Hierarchical multiple regression analyses were used to conduct moderation analyses for research questions 1 through 10. The PROCESS macro for SPSS program version 3.4, model 1 (Hayes, 2018) was used, applying 5,000 bootstrapping resamples with confidence intervals set at 95\%. The predictor variable and hypothesized moderator (age) were centered to avoid potentially problematic multicollinearity with the interaction term (Aiken \& West, 1991). Next, a series of hierarchical regression analyses were conducted and an interaction term computed to determine moderation. In the first step, the predictor variable and hypothesized moderator were included in the analysis. In the second step, the interaction term between the predictor variable and the hypothesized moderator was then included. This process was repeated for each research question examined.

Multiple regression analyses were conducted and known demographic covariates related to the outcomes that could explain some of the variance in the models were entered. Control 
variables that were entered into the model as covariates were: race/ethnicity, gender, education, COVID-19 diagnosis, and number of chronic health conditions. Controlling for variables allowed for levels of trust and the subsequent interaction with age to be examined independent of the variables in question. Categorical variables were dummy coded prior to analysis; for gender, males were coded as 0 and females as 1 , and for race/ethnicity, White/Caucasians were coded as 0 and Multicultural Minorities (Black/African American, Asian, Latinx, Native American or Pacific Islander, and Biracial) as 1. COVID-19 status was also dummy coded prior to analysis; not having had COVID-19 was coded as 0 and having a history of COVID-19 diagnosis was coded as 1 . Covariates were reported when they predicted significant variance in the model.

When a significant interaction was found, two methods were used to further examine how the relation between the independent and dependent variables changed at different values of the moderator: the Johnson-Neyman technique and simple slopes (Hayes \& Montoya, 2017). While the presence of a significant interaction suggests a moderation effect, it does not provide information about the specific conditions under which the predictor is significantly related to the outcome (Hayes \& Matthes, 2009; Holmbeck, 2002). The Johnson-Neyman technique and simple slopes were used to permit better comprehension of how the moderation effect performs at particular values of age (Hayes \& Montoya, 2017).

The Johnson-Neyman technique was used as a post-hoc analysis for examining interactions to test the specific regions where the interaction was significant. The JohnsonNeyman technique is used to identify the point or points along a continuous moderator (e.g., age) where the relation between $X$ and $Y$ transitions between statistically significant and nonsignificant (Hayes \& Montoya, 2017). Knowledge of these "regions of significance" of the effect of the independent variable on the dependent variable allows one to determine the conditions 
under which there is a relation (Hayes \& Montoya, 2017). The Johnson-Neyman analysis was used in the present study to determine at what age the interaction was significant based on the mean age of the sample.

Significant interactions were then plotted to further determine the interaction effects using representative points (i.e., $\pm 1 S D$ ), and simple slopes were examined. Simple slopes were graphed along the full continuum of possible scores for each health outcome variable for younger adults (1 SD below the mean), middle age adults (mean), and older adults (1 SD above the mean). Parameters for simple slopes are based on standard deviations and not set by the researcher. Since the mean age for the sample was around 52 years of age $\left(M_{\text {age }}=52.43, S D_{\text {age }}=\right.$ 17.18), 1 standard deviation below the mean for younger adults was around 35 years old, the mean of middle age was around 52 years old, and 1 standard deviation above the mean represented older age at around 69 years old.

Results for analyses examining whether age moderated the relation between trust in physicians and health outcome variables are reported in Table 4. Results for analyses examining whether age moderated the relation between trust in the healthcare system and health outcome variables are reported in Table 5. Each outcome variable is discussed in more detail below.

\section{Self-Rated Health}

\section{Research Questions 1. Does age moderate the relation between trust in physicians}

and self-rated health? A hierarchical multiple regression analysis was used to examine whether age moderated the relation between trust in physicians and self-rated health. There was a significant main effect of trust $(b=.3501, s e=.0553, p=.0000)$, such that trust was positively associated with self-rated health. Chronic health conditions predicted significant variance in the model $(b=-.4933, s e=.2637, p=.0252)$. That is, chronic health conditions were negatively 
associated with self-rated health. Results indicated that the overall model explained a significant portion of the variance in predicting self-rated health: $F(8,365)=7.6475, p<.05, R^{2}=.1210$, but the interaction was not significant, $b=-.0058$, s.e. $=.0031, p=.0586$, suggesting that age did not moderate the relation between trust in physicians and self-rated health.

\section{Research Questions 2. Does age moderate the relation between trust in the}

healthcare system and self-rated health? A hierarchical multiple regression analysis was used to examine whether age moderated the relation between trust in the healthcare system and selfrated health. Education predicted significant variance in the model $(b=.1180, s e=.0522, p=$ .0244). That is, education was positively associated with self-rated health. Results indicated that neither the overall model $\left(F(8,365)=1.7663, p=.0824, R^{2}=.0373\right)$, nor the interaction $b=$ -.0046 , s.e. $=.0043, p=.2857$ were significant, suggesting that age did not moderate the relation between trust in the healthcare system and self-rated health.

\section{Utilization of Healthcare Services}

\section{Research Questions 3. Does age moderate the relation between trust in physicians} and utilization of healthcare services? Hierarchical multiple regression analyses were used to examine whether age moderated the relation between trust in physicians and each measure of utilization of healthcare services (i.e., doctors' visits, emergency room visits, and hospital admissions). A moderation analysis was completed to test whether an interaction between age and trust in physicians predicted utilization of healthcare services for doctors' visits. There was a significant main effect of age $(b=.0428, s e=.0078, p=.0000)$, such that age was positively associated with utilization of doctors' visits. COVID-19 status predicted significant variance in the model $(b=1.4678, s e=.3271, p=.0000)$. That is, having been diagnosed with COVID-19 was positively associated with doctors' visits. Results indicated that the overall model explained 
a significant portion of the variance in predicting utilization of doctors' visits: $F(8,365)=$ $8.2768, p<.05, R^{2}=.1536$, but the interaction was not significant, $b=-.0024$, s.e. $=.0015, p=$ .1287 , suggesting age did not moderate the relation between trust in physicians and doctors' visits.

A hierarchical multiple regression analysis was used to examine whether age moderated the relation between trust in physicians and emergency room visits. There were significant main effects of trust $(b=-.1064, s e=.0345, p=.0022)$ and age $(b=.0388, s e=.0096, p=.0001)$, such that age was positively associated with emergency room visits and trust in physicians was negatively associated with emergency room visits. COVID-19 status predicted significant variance in the model $(b=1.5828, s e=.4015, p=.0001)$ That is, having been diagnosed with COVID-19 was positively associated with emergency room visits. Results indicated that the overall model explained a significant portion of the variance in predicting emergency room visits: $F(8,365)=6.5184, p<.05, R^{2}=.1250$, but the interaction was not significant, $b=$ -.0017 , s.e. $=.0019, p=.3766$, suggesting that age did not moderate the relation between trust in physicians and emergency room visits.

A hierarchical multiple regression analysis was used to examine whether age moderated the relation between trust in physicians and hospital admissions. COVID-19 status predicted significant variance in the model $(b=1.7319, s e=.4031, p=.0000)$. That is, having been diagnosed with COVID-19 was positively associated with hospital admissions. Results indicated that the overall model explained a significant portion of the variance in predicting hospital admissions: $F(8,365)=7.8827, p<.001, R^{2}=.1473$ and the interaction was also significant, $b=$ -.0047 , s.e. $=.0019, p=.0151$, suggesting that age moderated the relation between trust in physicians and hospitalizations. The post-hoc Johnson-Neyman statistic revealed that the 
interaction was not significant for individuals who were 44 years old and younger. In addition, participants 45 years of age and older demonstrated a stronger association between trust in physicians and hospital admissions. Simple slopes analysis was significant for two levels of the interaction — middle age and older age adults — indicating that both slopes were significantly different from zero. The general pattern suggested the effects of hospital admissions on trust in physicians became stronger with increasing age. The association between trust and hospitalizations was negative among middle and older aged adults. Among older adults, the slope was steeper, suggesting that lower levels of trust were associated with more hospital visits among older participants. See Figure 1 for the age moderation effects for hospital admissions.

\section{Research Questions 4. Does age moderate the relation between trust in the}

healthcare system and utilization of healthcare services? Hierarchical multiple regression analyses were used to examine whether age moderated the relation between trust in the healthcare system and each measure of utilization of healthcare services (i.e., doctors' visits, emergency room visits, and hospital admissions). A moderation analysis tested whether the interaction between age and trust in the healthcare system predicted utilization of healthcare services for doctors' visits. There were significant main effects of trust $(b=-.1940, s e=.0367, p$ $=.0000)$ and age $(b=.0396, s e=.0077, p=.0000)$, such that age was positively associated with doctors' visits, and trust was negatively associated with doctors' visits. COVID-19 status ( $b=$ 1.2422 , $s e=.3197, p=.0001)$ predicted significant variance in the model. That is, having been diagnosed with COVID-19 was positively associated with doctors' visits. Results indicated that the overall model explained a significant portion of the variance in predicting utilization of doctor's visits: $F(8,365)=12.0832, p<.05, R^{2}=.2094$, but the interaction was not 
significant, $b=-.0036$, s.e. $=.0020, p=.0659$, suggesting that age did not moderate the relation between trust in the healthcare system and doctor visits.

A hierarchical multiple regression analysis was used to examine whether age moderated the relation between trust in the healthcare system and emergency room visits. There were significant main effects of trust $(b=-.3196, s e=.0442, p=.0000)$ and age $(b=.0318, s e=$ $.0092, p=.0006)$, such that age was positively associated with emergency room visits and trust was negatively associated with emergency room visits. Chronic health conditions $(b=.3112$, se $=.1555, p=.0461)$ and COVID-19 status $(b=1.1705, s e=.3849, p=.0025)$ predicted significant variance in the model. That is, having been diagnosed with COVID-19 and chronic health conditions were positively associated with emergency room visits. Results indicated that the overall model explained a significant portion of the variance in predicting emergency room visits: $F(8,365)=12.4040, p<.05, R^{2}=.2138$, but the interaction was not significant, $b=$ -.0023 , s.e. $=.0023, p=.3357$ suggesting that age did not moderate the relation between trust in the healthcare system and emergency room visits.

A hierarchical multiple regression analysis was used to examine whether age moderated the relation between trust in the healthcare system and hospital admissions. There were significant main effects of trust $(b=-.2722$, se $=.0456, p=.0000)$ and age $(b=.0390$, se $=$ $.0095, p=.0001)$, such that age was positively associated with hospital admissions and trust was negatively associated with hospital admissions. COVID-19 status $(b=1.4117, s e=.3968, p=$ .0004) predicted significant variance in the model. That is, having been diagnosed with COVID19 was positively associated with hospital admissions. Results indicated that the overall model explained a significant portion of the variance in predicting utilization of hospital admissions: $F(8,365)=10.8600, p<.05, R^{2}=.1923$, but the interaction was not significant, $b=$ 
-.0024 , s.e. $=.0024, p=.3187$, suggesting that age did not moderate the relation between trust in the healthcare system and hospital admissions.

\section{Preference for Decision-Making}

\section{Research Questions 5. Does age moderate the relation between trust in physicians}

and preferred decision-making? A hierarchical multiple regression analysis was used to examine whether age moderated the relation between trust in physicians and preferred decisionmaking. There were significant main effects of trust $(b=-.0463, s e=.0081, p=.0000)$ and age $(b=.0067, s e=.0023, p=.0031)$, such that age was positively associated with preferred decision-making, and trust was negatively associated with preferred decision-making. COVID19 status predicted significant variance in the model $(b=.2421, s e=.0943, p=.0107)$. That is, having been diagnosed with COVID-19 was positively associated with preferred decisionmaking. Results indicated that the overall model explained a significant portion of the variance in predicting preference for decision-making: $F(8,365)=6.1095, p<.05, R^{2}=.1195$, but the interaction was not significant, $b=-.0006$, s.e. $=.0004, p=.1848$, suggesting that age did not moderate the relation between trust in physicians and preferred decision making.

\section{Research Questions 6. Does age moderate the relation between trust in the} healthcare system and preferred decision-making? A hierarchical multiple regression analysis was used to examine whether age moderated the relation between trust in the healthcare system and preference for decision-making. Results indicated that the overall model explained a significant portion of the variance in predicting preference for decision-making: $F(8,365)=$ $13.0127, p<.001, R^{2}=.2219$, and the interaction was also significant, $b=-.0012$, s.e. $=$ $.0005, p=.0237$, suggesting that age moderated the relation between trust and preference for decision making. The post-hoc Johnson-Neyman statistic was significant, indicating there was an 
interaction for all ages (i.e., younger, middle-aged, and older adults). Simple slopes analysis was significant for each level of the interaction, indicating that each slope was significantly different from zero. The general pattern suggested the effects of preferred decision-making on trust in the healthcare system became stronger with increasing age. The association between trust and preferred decision-making was negative among younger, middle, and older aged adults. However, among older adults the slope was steeper suggesting that lower levels of trust were associated with a preference for more autonomous decision-making among older participants. See Figure 2 for the age moderation effects for preference for decision-making.

\section{Adherence}

\section{Research Questions 7. Does age moderate the relation between trust in physicians}

and adherence? A hierarchical multiple regression analysis was used to examine whether age moderated the relation between trust in physicians and adherence. There was a significant main effect of trust $(b=.0530, s e=.0070, p=.0000)$, in which trust was positively associated with adherence. Education $(b=.0156, s e=.0061, p=.0109)$ and COVID-19 status $(b=.1778$, se $=$ $.0811, p=.0290)$ predicted significant variance in the model. That is, education and having been diagnosed with COVID-19 education were positively associated with adherence. Results indicated that the overall model explained a significant portion of the variance in predicting adherence: $F(8,365)=10.9697, p<.05, R^{2}=.1938$, but the interaction was not significant, $b=$ -.0003, s.e. $=.0004, p=.3859$, suggesting that age did not moderate the relation between trust in physicians and adherence.

\section{Research Questions 8. Does age moderate the relation between trust in the} healthcare system and adherence? A hierarchical multiple regression analysis was used to examine whether age moderated the relation between trust in the healthcare system and 
adherence. Education $(b=.0226, s e=.0065, p=.0005)$ and COVID-19 status $(b=.2099$, se $=$ $.0880, p=.0175)$ predicted significant variance in the model. That is, education and having been diagnosed with COVID-19 were positively associated with adherence. Results indicated that the overall model explained a significant portion of the variance in predicting adherence: $F(8,365)=$ $2.5751, p<.05, R^{2}=.0727$ but the interaction was not significant, $b=.0002$, s.e. $=.0005, p=$ .6962 , suggesting that age did not moderate the relation between trust in the healthcare system and adherence.

\section{Patient Satisfaction}

\section{Research Questions 9. Does age moderate the relation between trust in physicians}

and patient satisfaction? A hierarchical multiple regression analysis was used to examine whether age moderated the relation between trust in the healthcare system and patient satisfaction. COVID-19 status predicted significant variance in the model $(b=1.9130$, se $=$ $.9637, p=.0479)$. That is, having been diagnosed with COVID-19 was positively associated with patient satisfaction. Results indicated that the overall model explained a significant portion of the variance in predicting patient satisfaction: $F(8,365)=23.9266, p<.001, R^{2}=.3440$ and the interaction was also significant, $b=-.0150$, s.e. $=.0046, p=.0011$, suggesting that age does moderate the relation between trust in physicians and patient satisfaction. The post-hoc JohnsonNeyman statistic was significant, indicating there was an interaction among all levels of age. Simple slopes analysis was significant for each level of the interaction, which demonstrated that each slope was significantly different from zero. The general pattern suggested the effects of patient satisfaction on trust in physicians became stronger with increasing age. The association between trust and patient satisfaction was positive among younger, middle, and older aged adults. Among older adults, the slope was steeper suggesting that higher levels of trust were 
associated with greater patient satisfaction among older participants. See Figure 3 for the age moderation effects for patient satisfaction.

\section{Research Questions 10. Does age moderate the relation between trust in the}

healthcare system and patient satisfaction? A hierarchical multiple regression analysis was used to examine whether age moderated the relation between trust in the healthcare system and patient satisfaction. There was a significant main effect of trust $(b=.2875, s e=.1331, p=$ $.1314)$, such that trust was positively associated with patient satisfaction. Gender $(b=2.2520$, se $=.9521, p=.0185)$, education $(b=.2951, s e=.0855, p=.0006)$, and COVID-19 status $(b=$ 2.5426, $s e=1.1591, p=.0289)$ predicted significant variance in the model. That is, gender, education, and having been diagnosed with COVID-19 were positively associated with patient satisfaction. Results indicated that the overall model explained a significant portion of the variance in predicting patient satisfaction: $F(8,365)=3.5513, p<.05, R^{2}=.0722$ but the interaction was not significant, $b=-.0088$, s.e. $=.0071, p=.2133$, suggesting age did not moderate the relation between trust in the healthcare system and patient satisfaction.

\section{Discussion}

The current study examined whether age moderated the relation between two levels of trust, trust in physicians and trust in the healthcare system, and five selected health outcome variables of self-rated health, utilization of healthcare services, patient satisfaction, adherence, and patient's preference for decision-making. Through exploratory analysis, the results of the study found that age was a significant moderator for relations between trust in physicians and patient satisfaction, trust in physicians and hospital admissions, and trust in the healthcare system and preferred decision making. Moderation analyses of the relations among the other two levels of trust and health outcome variables examined found no moderation by age. 


\section{Moderating Role of Age}

Age as a moderator of trust in physicians and hospitalizations. Results from the

current study are consistent with previous research that trust in physicians is negatively related to the number of hospitalizations (e.g., Duckett et al., 2016; Ionescu-Ittu et al., 2007). There is also research showing a relation between age and number of hospitalizations (e.g., Jiang et al., 2018; Legramante et al., 2016), which is also consistent with the present study. The unique finding of the present study is that age moderated the relation between trust in physicians and number of hospital admissions. A closer examination of the findings revealed that the effect of age on this relation held for older adults but not younger adults.

A remaining question is why age would moderate the relation between trust in physicians and number of hospitalizations, and why that relation would hold only for older adults. The answer may lie in the fact that for older adults, trust in physicians is positively related to continuity of care (Gill et al., 2000; Liang et al., 2016). Continuity of care is also negatively related to likelihood of hospitalizations (Gill, 2000; Ionescu-Ittu et al., 2007; Mainous et al., 1998; Worrall \& Knight, 2006). In addition, older adults who trust their physicians are more likely to trust their physicians' medical judgment and expertise (Ionescu-Ittu et al., 2007). Therefore, when older adults trust their physicians, they are more likely to continue coming in for services including regular monitoring and check-ups (Gill et al., 2000) and are also more likely to reach out to their physicians to help manage medical problems when they do arise (Ionescu-Ittu et al., 2007). By following up with regular care and reaching out early when medical situations arise, older adults are able to address medical problems early in the office or over the telephone without further exacerbation of the problem instead of waiting until the problem warrants hospitalization (Ionescu-Ittu et al., 2007). This contributes to lower rates of 
avoidable hospitalizations (Gill et al., 2000; Ionescu-Ittu et al., 2007). Conversely, age was not a moderator for younger individuals, possibly because young adults have lower levels of trust in their physicians (Simon et al., 2014), and young adults are less likely to engage in continuity of care, have fewer checkups, and do not utilize healthcare services as frequently as middle-aged and older adults (e.g., Fortuna et al., 2015; Stroud et al., 2015; Wong et al., 2014).

\section{Age as a moderator of trust in the healthcare system and preferred decision-}

making. Results from the current study are consistent with the literature that trust in the healthcare system is negatively related to preferred decision-making (e.g., Chawla \& Arora, 2013; Ommen et al., 2011; Trachtenberg et al., 2005). That is, patients with higher levels of trust desire more of a passive role in their decision-making process. This was confirmed by the present findings. Previous research also shows that age is related to preferred decision-making (e.g., Chi et al., 2017; Lockenhoff, 2018; Trachtenberg et al., 2005), which was confirmed by the present results as well. The present study helps us understand the negative relation between trust in the healthcare system and preferred decision-making, in that it was moderated by age.

This leads to the question of why age might moderate the negative relation between trust in the healthcare system and preferred decision-making. First, older adults are more likely than younger adults to relegate decision making to their physicians (e.g., Ommen et al., 2011; Trachtenberg et al., 2005). For example, older adults who are more trusting are more likely to prefer more passive decision-making (Ommen et al., 2011; Trachtenberg et al., 2005). Another possible reason may be that older adults trust in their medical team has been reinforced through repeated interactions with the healthcare system (Dugan et al., 2005) and longer continuity of care (Mainous et al., 2001; Simon et al., 2014). Preferences for involvement in decision-making may also change with age potentially due to cohort effects, such that as adults age they prefer 
more passive decision-making roles (Flynn et al., 2006; Levinson et al., 2005). Older adults also report lower levels of health locus of control as they get older, which is significantly related to delegating decisional authority (Schneider et al., 2006).

Age as a moderator of trust in physicians and patient satisfaction. Considerable literature suggests that trust in physicians is related to patient satisfaction (e.g., Birkhauer er al., 2017; Lee \& Lin, 2011; Plantonova et al., 2009). This relation was confirmed in the present study. However, we do not completely understand why that might be the case. We also know that age is related to patient satisfaction (e.g., Chandra et al., 2019; Peck, 2011). The finding of the present study that age moderates the relation between truth in physicians and patient satisfaction helps us to understand this relation in more detail.

The effect of age on the relation between trust in physicians and patient satisfaction was stronger with older adults. One reason may be that older adults have had more time to build and strengthen trust-based relationships with their physicians and experience satisfaction through repeat encounters (Peck, 2011; Rocque \& Leanza, 2015). This explanation is supported by the fact that continuity of care is also positively related to patient satisfaction (Gill et al., 2000; Mainous et al., 2001). Another possible explanation could draw from the fact that older adults are more likely to visit their physician due to multiple chronic or comorbid health conditions (Bell et al., 2013; Gong et al., 2016). Patients also report needing to trust their physicians to be satisfied and remain with their physicians (Platonova et al., 2008). Therefore, older adults may have higher rates of patient satisfaction than younger adults because they are staying with physicians with whom they are more satisfied with to help manage their medical care (e.g., Alrubaiee \& Alkaa'ida, 2011; Kong et al., 2007). An additional explanation for this finding may be that trust in physicians is positively related to older adult patients' perception of physicians' 
empathy (Borracci et al., 2017), which, in turn, is positively related to patient satisfaction (e.g., Birkhauer er al., 2017; Hojat et al., 2010). That is, older adults who believe their physicians are more empathetic during their interactions are therefore more likely to trust their physicians and be more satisfied with the care they receive.

\section{$\underline{\text { Additional Analyses }}$}

Examination of the relations among predictor, criterion, and control variables revealed some interesting findings that are possibly worthy of further investigation in future research. COVID-19 diagnosis was positively related to preferred decision-making, such that participants diagnosed with COVID-19 were more likely to prefer autonomous decision-making roles. As was the case in this study, trust is negatively related to patient preference for decision-making (Chawla \& Arora, 2013; Kraetschmer et al., 2004; Lee \& Lin, 2010). Perhaps individuals who contracted COVID-19 were already less trusting to begin with or became less trusting through the experience of contracting the virus. It is also possible that lower levels of trust among patients diagnosed with COVID-19 may have resulted from the experience of navigating decisional uncertainty (e.g., Kother et al., 2021; Rutter et al., 2020). Lower levels may also have been due to a perceived loss of control (Jin et al., 2020), which can impact levels of trust (e.g., Tang et al., 2020; Torbit et al., 2016). The perceived risk of contracting the disease could also have played a role in these findings. For example, perceived risk for cancer is positively related to preferred decision-making process, such that high rates of risk perception are related to preference for autonomous decision-making roles (Dillard et al., 2010). The possible effects of perceived risk also are supported by a study by Kother et al. (2021) in which two groups participated in a decision-making task during the COVID-19 epidemic. One group was comprised of participants with preexisting conditions, and the other group was comprised of 
participants without preexisting conditions. Because of the preexisting medical condition, the participants in the preexisting condition group were at increased risk for severe progression after contracting COVID-19. Those participants reported higher decision participation preferences when presented with a COVID-19 case vignette than those in the non-risk group (Kother et al., 2021). One reason for this result may be that the interaction between an individual's perceived risk and disease severity produces a personal threat perception. The perceived threat, if viewed as high-risk, could act as a motivator for becoming actively involved in the decision-making process (Dillard et al., 2010). These results might warrant further exploration of the factors that contribute to the desire for more autonomous decision-making in the context of a life-threatening epidemic.

COVID-19 diagnosis was also negatively related to trust in the healthcare system. This finding might not be surprising in light of the public questioning of the adequacy of our healthcare system as it attempted to deal with the COVID-19 crisis (e.g., Jain et al., 2020; Kittleson, 2020). This is likely amplified by social media that have promulgated inaccurate information regarding the disease and its treatment (e.g., Allahverdipour, 2020; Gottlieb \& Dyer, 2020; Naeem et al., 2020). The "infodemic" (Gallotti et al., 2020) has contributed to serious threats to public health, by exposing individuals to potentially unreliable, misleading information about coronavirus that prevents the effective and timely adoption of recommended health behaviors (e.g., Gallotti et al., 2020; Islam et al., 2020). Sadly, because of the spread of misinformation via social media there has likely been an erosion of trust with potentially devastating consequences (Baker, 2020; Bogart et al., 2021). Trust in the healthcare system is incredibly beneficial for supporting the engagement in health behaviors that decrease the risk of contracting viruses during pandemics (e.g., Harris \& Sandal, 2021; Nezenga et al., 2020). For 
example, trust in the healthcare system is positively related to individuals following riskminimizing measures during pandemics (Harris \& Sandal, 2021) and the efficacy of officially recommended protection measures, including vaccination, handwashing, and wearing a mask during H1N1 (Gilles et al., 2011). Trust is also positively related to adherence with recommendations for H1N1 and SARS (Siegriest \& Zingg, 2014). Trust in the healthcare system is positively related to the likelihood of adopting preventive behaviors for Ebola, including exposure avoidance and vaccination (Vinck et al., 2019). Finally, there is a positive relation between trust in the healthcare system and patient knowledge (Bickell et al., 2009; Calnan \& Sanford, 2004). This knowledge is in turn related to adherence to treatment care and immunizations in cases of Ebola (Ajilore et al., 2017), malaria (Bruxvoort et al., 2014), measles (Phimmasane et al., 2010), and tuberculosis (Nezenga et al., 2020). With social media contributing to fractured trust in the healthcare system, there are concerns that coronavirus protocols will not continue to be followed and vaccination rates may also be affected (e.g., Loomba et al., 2021; Wilson \& Wiysonge, 2020). This is a unique period in time in which social media has played such an influential role in the dissemination of information and its impact on corresponding health behaviors (e.g., Gallotti et al., 2020). The COVID-19 crisis is the first pandemic in which social media and technology are being used on a global scale to both educate and undermine the spread of information to help control the virus (WHO, 2020). In light of these results, there is an opportunity to further explore the effects of social media on our trust in the healthcare system in general and particularly during pandemics.

\section{Limitations}

Several potential limitations of the current study need to be taken into consideration when interpreting results. With respect to demographics, the generalizability of these results to other 
studies may be limited due to the fact that participants were primarily Caucasian, male, and welleducated. This is relevant because education level is often associated with access to healthcare resources (Lynch, 2003; Schellekens \& Ziv, 2020) and the ability to maneuver through the healthcare system (Lynch, 2003), which contribute to health status and utilization of services. Additionally, gender status could have impacted health outcome variables examined in this study by contributing to differences in adherence, satisfaction, and self-rated health (e.g., Alaloola \& Albedaiwi, 2008; Serber et al., 2003). While the sample for this study was representative of the race/ethnicity of the United States in terms of Caucasian participants (U.S. Census Bureau, 2020), a more diverse population of individuals may interact with the healthcare system than the population recruited in our sample (e.g., Chen et al., 2016). This is relevant because ethnic disparities in health outcomes and access to healthcare services (Lee et al., 2009) impact healthcare-related levels of trust (LaViest et al., 2009), adherence (Xie et al., 2019), and satisfaction (Pinder et al., 2016).

The average score for the Wake Forest Physician Trust Scale (WFPTS) measure could have contributed to the results of this study. On the initial development and validation study for the WFPTS, Hall and colleagues (2002) reported the mean score was $40.8(S D=6.2)$ for the national sample of 959 community-dwelling participants. The mean score for the WFPTS in this current study was $34.52(S D=4.74)$. The mean values for the current study's sample were below the values obtained when the measure was used with Hall et al. (2002). The lower levels of trust may indicate differences in the sample between the current study and the sample recruited by Hall et al. (2002), which could influence the external validity of results.

The use of the one-item measure of adherence could also be a potential limitation in the study, as the item may not fully capture the relevant features of the construct it was developed to 
assess. This raises concerns about content validity. Single-item measures also lack a measurement statistic for internal consistency reliability, so information about psychometric properties of the measure is limited. An adherence assessment instrument with more items may be a more sensitive measure and provide additional information than the measure used here. There is also the need to consider the possibility that the younger participants in this study, in particular, may not have been given any instructions by their physicians and therefore were not able to accurately answer the question "How often do you follow what your physician prescribes for you?".

Additionally, this was an exploratory study and therefore, replication of results may be warranted to increase confidence in the data that was gathered. Furthermore, as a large number of analyses were conducted, this may have contributed to family-wise error, which should be taken into consideration when interpreting the results.

Finally, data collection occurred during the COVID-19 pandemic, which may have impacted overall level of trust. Level of trust in physicians reported in this study was lower than that of the standardization sample, perhaps due to differences in healthcare-related trust during the COVID-19 pandemic. Possible reasons why lower levels of trust were reported during the pandemic could be that the pandemic may have fractured healthcare-related trust (Baker, 2020) or contributed to lower confidence in physicians and the healthcare system, which is related to trust levels (Chan et al., 2020).

\section{Future Directions}

Results of the present study may offer several directions for future research. Further research is needed with a more diverse participant samples in terms of race/ethnicity, gender, and education level. Exploration of potential differences in levels of trust and the moderating role of 
age in more specific populations is needed. These populations should include individuals experiencing chronic health problems or terminal illness, as these individuals may be more likely to be reliant on their physicians for healthcare-related decisions.

Completing a similar study within a different pandemic (e.g., H1N1, SARS) would also provide information as to whether results are comparable or the COVID-19 pandemic uniquely yields differences in trust levels and related outcome variables. Additionally, a quarter of the current study's sample reported being diagnosed with COVID-19. It would be interesting to see if future research shows diagnosis status contributes to different levels of trust and whether this is a temporary change or affects trust levels over time.

The Health Care System Trust Scale, used in this study to assess participants' trust in the healthcare system, warrants further exploration. This scale was the reverse-coded version of the Revised Health Care System Distrust Scale (Shae et al., 2008). This measure was chosen because there were no current measures of trust in the healthcare system that adequately assessed the construct. Further research on the psychometric properties of this scale is needed using more diverse participant samples across a variety of settings (e.g., outpatient settings, inpatient facilities, long-term-care facilities). In the future, this instrument could be used to study mistrust and factors that contribute to or mitigate it.

Future research could utilize more complex, higher-order statistical analyses to further assess the role of age in relation to the levels of trust and health outcome variables. It is likely that the relations examined in this study may be more complex than revealed by the analyses used to assess these relations. Mediated moderation, moderated mediation, and higher-order moderation studies are needed to help further assess these relations, targeting other variables as predictors like race/ethnicity (LaViest et al., 2009), institutional betrayal (Smith, 2017), 
personality traits (Donnellan \& Lucas, 2008), health locus of control (Brincks et al., 2010), and even health literacy (Tsai et al., 2018).

Future research should continue to focus on the role of age in relations of trust and health outcome variables. Qualitative research may help explore age-related differences in trust, including asking older adults about aspects of physician behavior and about the healthcare system that leads to trust or mistrust. More research into whether the quality of the relationship between patient and physician, the nature of the relationship, and the length of time of the relationship affect trust levels is also warranted. Additionally, physicians may want to tailor treatment to patients' preferred involvement in medical decisions based on patient age and trust levels. This could be accomplished by measuring levels of trust on assessment screeners at doctor's visits, which could be particularly useful among individuals whose levels of trust of physicians and the healthcare system on the screeners are low. Furthermore, research focused of individuals with high levels of healthcare-related trust can potentially help us understand how one could augment healthcare utilization by determining successful ways to engender trust between patient and physician and patient and healthcare system.

There may also be practical significance of the study findings in terms of the moderating effect of age on the relation between trust in physicians and hospital admissions. Specifically, the results in this study indicated that lower levels of trust were associated with more hospital visits among older participants and that older adults who were more trusting had fewer hospital visits on average than their less trusting peers. This finding could help in developing targeted interventions to improve trust among older adults, as increasing trusting relationships between patients and physicians may help reduce the frequency of older adult hospitalizations and lower healthcare costs. Older adults are also the most frequent users of healthcare services (Dugan et 
al., 2005; Nie et al., 2010). It is also possible this finding may potentially have implications for insurance companies, health insurance programs (e.g., Medicare, Medicaid), and even hospitals in terms of managing costs by decreasing avoidable hospitalizations.

Finally, this could potentially be a pivotal moment in healthcare for building or rebuilding trust. The current coronavirus pandemic has created additional threats to trust (Baker, 2020). A recent meta-analysis of the psychological impacts of the COVID-19 virus quarantine on individuals identified limited communication from public health officials as one of the top stressors during periods of quarantine (Brooks et al., 2020). Limited communication has contributed to the spread of misinformation in healthcare (Arora et al., 2020) and lack of trust in the system as a whole (Baker, 2020). Physicians have reported that long-time patients question their advice about safe COVID-19 protocol (Kittleson, 2020) and that the presence of conflicting messages about the pandemic have eroded the already fractured trust in the healthcare system (Jain et al., 2020). Rebuilding trust is essential to help target these threats to individuals' health and to encourage trust in the coronavirus vaccination recommendations. Data gathered during the $\mathrm{H} 1 \mathrm{~N} 1$ influenza pandemic indicated that trust in physicians was related to patient's intentions to get vaccinated and that patients who distrusted their physicians were more likely to indicate that they did not plan on getting vaccinated (Taha et al., 2013). Additionally, trust in healthcare organizations longitudinally predicted vaccination rates for the H1N1 influenza pandemic (Gilles et al., 2011). The relation between trust in the healthcare system and vaccination rates may be especially pertinent in communities who have high rates of mistrust in the system, including people of color, to help improve COVID-19 vaccination rates. Racial disparities are evident regarding who is choosing to get vaccinated (Bogart et al., 2021; Razai et al., 2021). Trust in 
physicians and the healthcare system may help mitigate vaccine hesitancy and help encourage vaccinations in the future.

\section{Conclusion}

Results from the current study furthered understanding about the role of age as a moderator and expanded discussions of trust in healthcare. Prior research has linked trust to the five health outcome variables examined in this study and age to these health outcome variables, but there has been a lack of research exploring how all of these variables are connected. While both levels of trust and health outcome variables change across the lifespan, the role of age as a moderator of these relations had previously been unexplored. In this study, age moderated the relations between trust in physicians and healthcare utilization of hospital admissions, trust in physicians and patient satisfaction, and trust in the healthcare system and preferred decision making. The finding of the present study that age moderates these relations helps us understand these relations and that these relations vary based on age. This study is the first step toward a better understanding of the role of age in predicting health outcomes. Based on these findings, future researchers should consider incorporating a lifespan perspective when assessing levels of trust and health outcome variables. Further development of targeted interventions to improve levels of trust in physicians and the healthcare system could also be beneficial, particularly for older adults. 


\section{References}

Abel, W. M., \& Efird, J. T. (2013). The association between trust in health care providers and medication adherence among black women with hypertension. Frontiers in Public Health, 1, 66-72. doi:10.3389/fpubh.2013.00066

Adams, L. B., Richmond, J., Corbie-Smith, G., \& Powell, W. (2017). Medical mistrust and colorectal cancer screening among African Americans. Journal of Community Health, 42, 1044-1061. doi:10.1007/s10900-017-0339-2

Afilalo, J., Marinovich, A., Afilalo, M., Colacone, A., Léger, R.,...Giguère, C. (2004). Nonurgent emergency department patient characteristics and barriers to primary care. Academic Emergency Medicine, 11, 1302-1310. doi:10.1197/j.aem.2004.08.032

Aiken, L. S., \& West, S. G. (1991). Multiple regression: Testing and interpreting interactions. Thousand Oaks, CA: Sage.

Ajilore, K., Atakiti, I., \& Onyenankeya, K. (2017). College students' knowledge, attitudes and adherence to public service announcements on Ebola in Nigeria: Suggestions for improving future Ebola prevention education programmes. Health Education Journal, 76, 648-660. doi:10.1177/0017896917710969

Alaloola, N. A., \& Albedaiwi, W. A. (2008). Patient satisfaction in a Riyadh tertiary care centre. International Journal of Health Care Quality Assurance, 21, 630-637. doi:10.1108/09526860810910113

Alasad, J., Abu Tabar, N., \& AbuRuz, M. E. (2015). Patient satisfaction with nursing care: Measuring outcomes in an international setting. Journal of Nursing Administration, 45, 563-568. doi:10.1097/NNA.0000000000000264.

Allahverdipour, H. (2020). Global challenge of health communication: Infodemia in the 
Coronavirus Disease (COVID-19) Pandemic. Journal of Education and Community Health, 7, 65-67.

Alrubaiee, L., \& Alkaa'ida, F. (2011). The mediating effect of patient satisfaction in the patients' perceptions of healthcare quality-patient trust relationship. International Journal of Marketing Studies, 3, 103-127. doi:10.5539/ijms.v3n1p103

Amstadter, A. B., Begle, A. M., Cisler, J. M., Hernandez, M. A., Muzzy, W., \& Acierno, R. (2010). Prevalence and correlates of poor self-rated health in the United States: The national elder mistreatment study. The American Journal of Geriatric Psychiatry, 18, 615-623. doi:10.1097/JGP.0b013e3181ca7ef2

Andersen, R. M. (2008). National health surveys and the behavioral model of health services use. Medical Care, 46. 647-653. doi:10.1097/MLR.0b013e31817a835d

Armstrong, K., Rose, A., Peters, N., Long, J. A., McMurphy, S., \& Shea, J. A. (2006). Distrust of the health care system and self-reported health in the United States. Journal of General Internal Medicine, 21, 292-297. doi:10.1111/j.1525-1497.2006.00396.x

Arora, N. K., \& McHorney, C. A. (2000) Patient preferences for medical decision making: Who really wants to participate? Medical Care, 38, 335-341.

Arora, V. M, Madison, S., \& Simpson, L. (2020). Addressing medical misinformation in the patient-clinician relationship. JAMA. 23, 2367-2368. doi:10.1001/jama.2020.4263

Bachinger, S. M., Kolk, A. M., \& Smets, E. M. (2009). Patients' trust in their physicianpsychometric properties of the Dutch version of the "Wake Forest Physician Trust Scale". Patient Education and Counseling. 76. 126-131. doi:10.1016/j.pec.2008.11.020.

Baker, D. W. (2020). Trust in health care in the time of COVID-19. JAMA. 23, 2373-2375. doi:10.1001/jama.2020.23343 
Balkrishnan, R., Dugan, E., Camacho, F. T., \& Hall, M. A. (2003). Trust and satisfaction with physicians, insurers, and the medical profession. Medical Care. 41.1058-1064. doi:10.1097/01.MLR.0000083743.15238.9F

Bell, R. A., Arcury, T. A., Ip, E., Grzywacz, J. G., Nguyen, H., Kirk, J. K....Quandt, S. A. (2013). Correlates of physician trust among rural older adults with diabetes. American Journal of Health Behavior, 37, 660-666. doi:10.5993/AJHB.37.5.10

Benjamins, M. R. (2006). Religious influences on trust in physicians and the health care system. The International Journal of Psychiatry in Medicine, 36, 6983. doi:10.2190/EKJ2-BCCT-8LT4-K01W

Berinsky, A., Huber, G., \& Lenz, G. (2012). Evaluating online labor markers for experimental research: Amazon.com’s Mechanical Turk. Political Analysis, 20, 351-368. doi:10.1093/pan/mpr057

Berrios-Riveria, J. P., Street, R. L., Garcia Popa-Lisseanu, M. G., Kallen, M. A., Richardson, M.N., Janssen, N. M., .....Suarez-Almazor, M.E. (2006). Trust in physicians and elements of the medical interaction in patients with rheumatoid arthritis and systemic lupus erythematosus. Arthritis \& Rheumatology, 55, 385-393. doi:10.1002/art.21988

Best, R., \& Charness, N. (2015). Age differences in the effect of framing on risky choice: A meta-analysis. Psychology and Aging, 30, 688-698. doi:10.1037/a0039447

Bickell, N. A., Weidmann, J., Fei, K., Lin, J. J., \& Leventhal, H. (2009). Underuse of breast cancer adjuvant treatment: patient knowledge, beliefs, and medical mistrust. Journal of Clinical Oncology, 27, 5160-5167. doi:10.1200/JCO.2009.22.9773

Birkhäuer, J., Gaab, J., Kossowsky, J., Hasler, S., Krummenacher, P., Werner, C., \& Gerger, H. (2017). Trust in the health care professional and health outcome: A meta-analysis. PloS 
One, 12, e0170988. doi:10.1371/journal.pone.0170988

Bjørnskov, C. (2003). The happy few: Cross-country evidence on social capital and life satisfaction. Kyklos, 56, 3-16. doi:10.1111/1467-6435.00207

Blackwell, D. L. , Martinez, M. E. , Gentleman, J. F. , Sanmartin, C. \& Berthelot, J. (2009). Socioeconomic status and utilization of health care services in Canada and the United States. Medical Care, 47, 1136-1146. doi:10.1097/MLR.0b013e3181adcbe9.

Bogart, L. M., Ojikutu, B. O., Tyagi, K., Klein, D. J., Mutchler, M. G., Dong, ...Kellman, S. (2021). COVID-19 related medical mistrust, health impacts, and potential vaccine hesitancy among black Americans living with HIV. Journal of Acquired Immune Deficiency Syndromes, 86, 200-207. doi:10.1097/QAI.0000000000002570

Bombak, A. E. (2013). Self-rated health and public health: A critical perspective. Frontiers in Public Health, 1, 15-23. doi:10.3389/fpubh.2013.00015

Bonds, D. E., Camacho, F., Bell, R. A., Duren-Winfield, V. T., Anderson, R. T., \& Goff, D. C. (2004). The association of patient trust and self-care among patients with diabetes mellitus. BMC Family Practice, 5, 1-7. doi:10.1186/1471-2296-5-26

Borracci, R. A., Doval, H. C., Celano, L., Ciancio, A., Manente, D., \& Calderón, J. G. (2017). Patients' perceptions of argentine physicians' empathy based on the Jefferson scale of patient's perceptions of physician empathy: Psychometric data and demographic differences. Education and Health, 30, 19-25.

Borum, R. (2010). The science of interpersonal trust. Mental Health Law \& Policy Faculty Publications. 574. 1-55.

Boulware, L. E., Cooper, L. A., Ratner, L. E., LaVeist, T. A., \& Powe, N. R. (2003). Race and trust in the health care system. Public Health Reports, 118, 358-365. 
doi:10.1093/phr/118.4.358

Boume, P. A., \& McGrowder, D. A. (2009). Health status of patients with self-reported chronic diseases in Jamaica. North American Journal of Medical Sciences, 1, 356-364. doi:10.4297/najms.2009.7356

Brennan, N., Barnes, R., Calnan, M., Corrigan, O., Dieppe, P., \& Entwistle, V. (2013). Trust in the health-care provider-patient relationship: a systematic mapping review of the evidence base, International Journal for Quality in Health Care, 25, 682688. doi:10.1093/intqhe/mzt063

Brincks, A. M., Feaster, D. J., Burns, M. J., \& Mitrani, V. B. (2010). The influence of health locus of control on the patient-provider relationship. Psychology, Health \& Medicine, 15, 720-728. doi:10.1080/13548506.2010.498921

Brooks, S. K., Webster, R. K., Smith, L. E., Woodland, L., Wessley, S., Greenberg, N., \& Rubin, G. J. (2020). The psychological impact of quarantine and how to reduce it: Rapid review of the evidence. The Lancet , 395 , 912-920. doi:10.1016/S0140-6736(20)30460-8

Brown, M. T., \& Bussell, J. K. (2011). Medication adherence: WHO cares?. Mayo Clinic Proceedings, 86, 304-314. doi:10.4065/mcp.2010.0575

Bruxvoort, K., Goodman, C., Kachur, S. P., \& Schellenberg, D. (2014). How patients take malaria treatment: a systematic review of the literature on adherence to antimalarial drugs. PloS one, 9, e84555. doi:10.1371/journal.pone.0084555

Buhrmester, M., Kwang, T., \& Gosling, S. D. (2011). Amazon's Mechanical Turk: A new source of inexpensive, yet high-quality, data? Perspectives on Psychological Science, 6, 3-5. doi:10.1177/1745691610393980

Burkhart, P. V., \& Sabaté, E. (2003). Adherence to long-term therapies: Evidence for action. 
Journal of Nursing Scholarship, 35, 207-215.

Calnan, M., \& Rowe, R. (2008). Trust Matters in Health Care. Open University Press, McGrawHill

Calnan, M. W., \& Sanford, E. (2004). Public trust in health care: The system or the doctor?. Quality \& Safety in Health Care, 13, 92-97. doi:10.1136/qshc.2003.009001

Carstensen, L. L. (2006). The influence of a sense of time on human development. Science, 31, 1913-1915. doi:10.1126/science. 1127488

Castle, E., Eisenberger, N. I., Seeman, T. E., Moons, W. G., Boggero, I. A., Grinblatt, M. S., \& Taylor, S. E. (2012). Neural and behavioral bases of age differences in perceptions of trust. Proceedings of the National Academy of Sciences of the United States of America, 109, 20848-20852. doi:10.1073/pnas.1218518109

Centers for Disease Control and Prevention. (2020). People at Increased Risk: Older Adults. https://www.cdc.gov/coronavirus/2019-ncov/need-extra-precautions/olderadults.html\#: :text=Help\%20at\%20Home,The\%20risk\%20for\%20severe $\% 20$ illness $\% 20$ with\%20COVID\%2D19\%20increases\%20with,than\%20people\%20in\%20their\%2050s.

Cepeda, M. S., Reps, J., Kern, D. M., \& Stang, P. (2020). Medical conditions predictive of selfreported poor health: Retrospective cohort study. JMIR Public Health and Surveillance, 6, e13018. doi:10.2196/13018

Chamberlain, A. M., Manemann, S. M., Dunlay, S. M., Spertus, J. A., Moser, D. K., Berardi, C., ..... Roger, V. L. (2014). Self-rated health predicts healthcare utilization in heart failure. Journal of the American Heart Association, 3, e000931. doi:10.1161/JAHA.114.000931

Chandra, S., Ward, P., \& Mohammadnezhad, M. (2019). Factors associated with patient 
satisfaction in outpatient department of suva sub-divisional health center, Fiji, 2018: A mixed method study. Frontiers in Public Health, 7, 183-194.

doi:10.3389/fpubh.2019.00183

Chawla, N., \& Arora, N. K. (2013). Why do some patients prefer to leave decisions up to the doctor: lack of self-efficacy or a matter of trust?. Journal of Cancer Survivorship, 7, 592601. doi:10.1007/s11764-013-0298-2

Chen, J., Vargas-Bustamante, A., Mortensen, K., \& Ortega, A. N. (2016). Racial and ethnic disparities in health care access and utilization under the Affordable Care Act. Medical Care, 54, 140-146. doi:10.1097/MLR.0000000000000467

Chen, W., Feng, Y., Fang, J., Wu, J., Huang, X., Wang, X...Zhang, M. (2020). Effect of trust in primary care physicians on patient satisfaction: a cross-sectional study among patients with hypertension in rural China. BMC Family Practice, 21, 196-204.

doi:10.1186/s 12875-020-01268-w

Chewning, B., Bylund, C. L., Shah, B., Arora, N. K., Gueguen, J. A., \& Makoul, G. (2012). Patient preferences for shared decisions: A systematic review. Patient Education and Counseling, 86, 9-18. doi:10.1016/j.pec.2011.02.004

Chi, W. C., Wolff, J., Greer, R., \& Dy, S. (2017). Multimorbidity and decision-making preferences among older adults. Annals of Family Medicine, 15, 546-551. doi:10.1370/afm.2106

Conn, V. S., Ruppar, T. M., Enriquez, M., \& Cooper, P. S. (2016). Patient-centered outcomes of medication adherence interventions: Systematic review and meta-analysis. Value in Health: The Journal of the International Society for Pharmacoeconomics and Outcomes Research, 19, 277-285. doi:10.1016/j.jval.2015.12.001 
Coulson, A. (1998). Trust and contract in public sector management, in A. Coulson (Ed.). Trust and contracts: Relationships in local government, health and public services. The Polity Press.

Cuffee, Y. L., Hargraves, J. L., Rosal, M., Briesacher, B. A., Schoenthaler, A., Person, S., Hullett, S., \& Allison, J. (2013). Reported racial discrimination, trust in physicians, and medication adherence among inner-city African Americans with hypertension. American Journal of Public Health, 103, e55-e62. doi:10.2105/AJPH.2013.301554

Dale, S. K., Bogart, L. M., Wagner, G. J., Galvan, F. H., \& Klein, D. J. (2016). Medical mistrust is related to lower longitudinal medication adherence among African-American males with HIV. Journal of Health Psychology, 21, 1311-1321. doi:10.1177/1359105314551950

Deber, R. B., Kraetschmer, N., \& Irvine, J. (1996). What role do patients wish to play in treatment decision making? Archives of Internal Medicine, 156, 1412-1420.

Deber, R. B., Kraetschmer, N., Urowitz, S., \& Sharpe, N. (2007). Do people want to be autonomous patients? Preferred roles in treatment decision-making in several patient populations. Health Expectations: An International Journal of Public Participation in Health Care and Health Policy, 10, 248-258. doi:10.1111/j.1369-7625.2007.00441.x

DeSalvo, K. B., Fan, V. S., McDonnell, M. B., \& Fihn, S. D. (2005). Predicting mortailty and healthcare utilization with a single-question. Health Services Research, 40, 12341246. doi:10.1111/j.1475-6773.2005.00404.x

Dillard, A. J., Couper, M. P., \& Zikmund-Fisher, B. J. (2010). Perceived risk of cancer and patient reports of participation in decisions about screening: The DECISIONS study. Medical Decision Making, 30, 96S-105S. doi:10.1177/0272989X10377660 
Dirks, K. T., \& Ferrin, D. L. (2001). The role of trust in organizational settings. Organization Science, 12, 450-467. doi:10.1287/orsc.12.4.450.10640

Donnellan, M. B., \& Lucas, R. E. (2008). Age differences in the Big Five across the life span: evidence from two national samples. Psychology and Aging, 23, 558-566. doi:10.1037/a0012897

Duckett, J., Hunt, K., Munro, N., \& Sutton, M. (2016). Does distrust in providers affect healthcare utilization in China?. Health Policy and Planning, 31, 1001-1009. doi:10.1093/heapol/czw024

Egede, L. E., \& Ellis, C. (2008). Development and testing of the Multidimensional Trust in Health Care Systems Scale. Journal of General Internal Medicine, 23, 808-815. doi:10.1007/s11606-008-0613-1

El-Nagger, N. S, Ahmed, S. M. A, Elsayed, L. A, \& Khamis, H. M. A. (2013). Patients satisfaction regarding nursing care provided in different hospitals in Makkah AL Mukramah. Life Science Journal, 10, 421-429

Eng, H. S., Kaur, G., Wafa, S. R., Zulkifli, S., Zakaria, S., \& Omar, R. (2006). Post-cardiac surgery patient satisfaction with quality nursing care at Institute Jantung Negara (IJN). Medicine Health, 1, 14-19.

Evans, A. M., \& Revelle, W. (2008). Survey and behavioral measurements of interpersonal trust. Journal of Research in Personality, 42, 1585-1593. doi:10.1016/j.jrp.2008.07.011

Eveleigh, R. M., Muskens, E., van Ravesteijn, H., van Dijk, I., van Rijswijk, E., \& Lucassen, P. (2012). An overview of 19 instruments assessing the doctor-patient relationship: Different models or concepts are used. Journal of Clinical Epidemiology, 65, 10-15. doi:10.1016/j.jclinepi.2011.05.011 
Fan, V. S., Burman, M., McDonell, M. B., \& Fihn, S. D. (2005). Continuity of care and other determinants of patient satisfaction with primary care. Journal of General Internal Medicine, 20, 226-233. doi:10.1111/j.1525-1497.2005.40135.x

Faul, F., Erdfelder, E., Buchner, A., \& Lang, A. G. (2013). G*Power Version 3.1.7 [computer software]. Uiversität Kiel, Germany. http://www.softpedia.com/get/Science-CAD/GPower.shtml

Field, A. (2013). Discovering statistics using IBM SPSS statistics. Sage. Publications.

Fingerman, K. L., Berg, C. A., Smith, J., \& Antonucci, T. C. (Eds). (2011), Handbook of Life Span Development. Springer.

Flaherty, K. E., \& Pappas, J. M. (2000). The role of trust in salesperson-sales manager relationships. Journal of Personal Selling and Sales Management, 20. 271-278.

Flynn, K. E., Smith, M. A., \& Vanness, D. (2006). A typology of preferences for participation in healthcare decision making. Social Science \& Medicine, 63, 1158-1169. doi:10.1016/j.socscimed.2006.03.030

Fortuna, R. J., Robbins, B. W., \& Halterman, J. S. (2009). Ambulatory care among young adults in the United States. Annuals of Internal Medicine, 151, 379-385. doi:10.7326/00034819-151-6-200909150-00002

Fortune, E. E., Shotwell, J. J., Buccellato, K., \& Moran, E. (2016). Factors predicting desired autonomy in medical decisions: Risk-taking and gambling behaviors. Health Psychology Open, 3, e2055102916651267. doi:10.1177/2055102916651267

Fox, S. A., Heritage, J., Stockdale, S. E., Asch, S. M., Duan, N., \& Reise, S. P. (2009). Cancer screening adherence: Does physician-patient communication matter? Patient Education and Counseling, 75, 178-184. doi:10.1016/j.pec.2008.09.010 
Frazier, L. M., Johnson, P. D., \& Fainshmidt, S. (2013). Development and validation of a propensity to trust scale. Journal of Trust Research, 3, 76-97, doi:10.1080/21515581.2013.820026

Freburger, J. K., Callahan, L. F., Currey, S. S., \& Anderson, L. A. (2003) Use of the Trust in Physician Scale in patients with rheumatic disease: Psychometric properties and correlates of trust in the rheumatologist. Arthritis Care \& Research, 49. 51-58. doi:10.1002/art.10925

Fuertes, J. N., Toporovsky, A., Reyes, M., \& Osborne, J. B. (2017). The physician-patient working alliance: Theory, research, and future possibilities. Patient Education and Counseling, 100, 610-615. doi:10.1016/j.pec.2016.10.018

Gagnon, M., Hébert, R., Dubé, M., \& Dubois, M. F. (2006). Development and validation of the Health Care Satisfaction Questionnaire (HCSQ) in elders. Journal of Nursing Measurement, 14, 190-204. doi:10.1891/jnm-v14i3a004.

Gallotti, R., Valle, F., Castaldo, N. Sacco., P., \& De Domencio, M. (2020). Assessing the risks of 'infodemics’ in response to COVID-19 epidemics. Nature Human Behavior, 4, 1285 1293. doi:10.1038/s41562-020-00994-6

George, D. \& Mallery, M. (2010). SPSS for Windows Step by Step: A Simple Guide and Reference, 17.0 update (10a ed.) Pearson.

George, P. P., Heng, B. H., De Castro Molina, J. A., Wong, L. Y., Wei Lin, N. C., \& Cheah, J. T. (2012). Self-reported chronic diseases and health status and health service utilizationresults from a community health survey in Singapore. International Journal for Equity in Health, 11, 44-52. doi:10.1186/1475-9276-11-44

Gerich, J., Moosbrugger, R., \& Heigl, C. (2020). Health literacy and age-related health-care 
utilization: A multi-dimensional approach. Ageing and Society, 1-22.

doi:10.1017/S0144686X20001609

Giddens, A. (1994). Risk, trust, reflexivity. In: Beck, U., Giddens, A., Lash, S., (eds). Reflexive Modernization. Polity Press.

Giddens, A. (1990). The consequences of modernity. Stanford University Press.

Gill, J. M., Mainous, A. G., \& Nsereko, M. (2000). The effect of continuity of care on emergency department use. Archive of Family Medicine, 9, 333-338. doi:10.1001/archfami.9.4.333

Gilles, I., Bangerter, A., Clémence, A., Green, E. G., Krings, F., Staerklé, C., \& Wagner-Egger, P. (2011) Trust in medical organizations predicts pandemic (H1N1) 2009 vaccination behavior and perceived efficacy of protection measures in the Swiss public. European Journal of Epidemiology, 26, 203-210. doi:10. 1007/s10654-011-9577-2

Gilson, L. (2003). Trust and the development of health care as a social institution. Social Science and Medicine. 56. 1453-1468. doi:10.1016/S0277-9536(02)00142-9.

Gilson, L. (2005). Trust in health care: Theoretical perspectives and research needs. Journal of Health Organization and Management. 20. 359-375. doi:10.1108/14777260610701768.

Glaesmer, H., Brähler, E., Martin, A., Mewes, R., \& Rief, W. (2012). Gender differences in healthcare utilization: The mediating effect of utilization propensity. Journal of Applied Social Psychology, 42, 1266-1279. doi:10.1016/j.pec.2016.02.009 0738-3991

Gong, C. H., Kendig, H., \& He, X. (2016). Factors predicting health services use among older people in China: An analysis of the China Health and Retirement Longitudinal Study 2013. BMC Health Services Research, 16, 63-72. doi:10.1186/s12913-016-1307-8

Goold, S. D., Fessler, D., \& Moyer, C. A. (2006). A measure of trust in insurers. Health Services 
Research, 41, 58-78. doi:10.1111/j.1475-6773.2005.00456.x

Gordon, H. S., Street, R. L., Jr, Sharf, B. F., Kelly, P. A., \& Souchek, J. (2006). Racial differences in trust and lung cancer patients' perceptions of physician communication. Journal of Clinical Oncology. 24, 904-909. doi:10.1200/JCO.2005.03.1955

Gottlieb, M. and Dyer, S. (2020). Information and disinformation: Social media in the COVID19 crisis. Academic Emergency Medicine, 27, 640-641. doi:10.1111/acem.14036

Graf, A. \& Patrick, J. (2016). Self-Assessed health into late adulthood: Insights from a lifespan perspective. GeroPsych, 29, 177-187. doi:10.1024/1662-9647/a000156.

Graham, J. L., Shahani, L., Grimes, R. M., Hartman, C., \& Giordano, T. P. (2015). The influence of trust in physicians and trust in the healthcare system on linkage, retention, and adherence to HIV care. AIDS Patient Care and STDs, 29, 661-667. doi:10.1089/apc.2015.0156

Greenspan, S., Goldberg, D., Weimer, D., \& Basso, A. (2000). Interpersonal trust and common group in electronically medicated communication. Paper presented at the annual meeting of the Computer Supported Cooperative Work. Philadelphia, PA.

Gregório, M., Teixeira, A., Páscoa, R., Baptista, S., Carvalaho, R., \& Martins, C. (2020). The Problem-Solving Decision-Making scale-translation and validation for the Portuguese language: A cross-sectional study. BMJ Open, 10, e003365. doi:10.1136/bmjopen-2019033625

Guatam, R., Roggina, T., Moss, A., \& Litman, L. (2019, August 18). Recruiting older adults online. https://www.cloudresearch.com/resources/blog/recruiting-olderadults-online/ 
Gupta, S., Brenner, A. T., Ratanawongsa, N., \& Inadomi, J. M. (2014). Patient trust in physician influences colorectal cancer screening in low-income patients. American Journal of Preventive Medicine, 47, 417-423. doi:10.1016/j.amepre.2014.04.020

Hall, M. A., Camacho, F., Dugan, E., \& Balkrishnan, R. (2002). Trust in the medical profession: conceptual and measurement issues. Health Services Research, 37, 1419-1439. doi:10.1111/1475-6773.01070

Hall, M. A., Dugan, E., Zheng, B. \& Mishra, A. (2001). Trust in physicians and medical institutions: What is it, can it be measured and does it matter? Milbank Quarterly, 79, 613-639.

Hall, M. A., Zheng, B., Dugan, E., Camacho, F., Kidd, K. E., Mishra, A., \& Balkrishan, R. (2002). Measuring patients' trust in their primary care providers. Medical Care Research and Review, 59, 293-318. doi:10.1177/1077558702059003004

Hämmig, O., Gutzwiller, F., \& Kawachi, I. (2014). The contribution of lifestyle and work factors to social inequalities in self-rated health among the employed population in Switzerland. Social Science and Medicine, 121, 74-84. doi:10.1016/j.socscimed.2014.09.041.

Hardie, E. A., \& Crichley, C. R. (2008). Public perceptions of Australia's doctors, hospitals and health care systems. Medical Journal of Australia, 189, 210-214.

Harju, B. L., Wuensch, K. L., Kuhl, E. A., \& Cross, N. J. (2006). Comparison or rural and urban residents' implicit and explicit attitudes related to seeking medical care. Journal of Rural Health, 22, 359-363. doi:10.1111/j.1748-0361.2006.00058.x

Harris, S.M., \& Sandal, G. M. (2021). COVID-19 and psychological distress in Norway: The role of trust in the healthcare system. Scandinavian Journal of Public Health, 49, 96-103. doi:10.1177/1403494820971512 
Hayes, A. F., \& Little, T. (2018). Introduction to mediation, moderation, and conditional process analysis: A regression-based approach (2 ${ }^{\text {nd }}$ edition). New York, NY: Guilford Press.

Hayes, A. F., \& Matthes, J. (2009). Computational procedures for probing interactions in OLS and logistic regression: SPSS and SAS implementations. Behavior Research Methods, 41, 924-936. doi:10.3758/BRM.41.3.924

Hayes, A.F., \& Montoya, A. K. (2017) A tutorial on testing, visualizing, and probing an interaction involving a multicategorical variable in linear regression analysis. Communication Methods and Measures, 11, 1-30, doi:10.1080/19312458.2016.1271116

Hays, R. D., Bjorner, J. B., Revicki, D. A., Spritzer, K. L., \& Cella, D. (2009). Development of physical and mental health summary scores from the patient-reported outcomes measurement information system (PROMIS) global items. Quality of Life Research: An International Journal of Quality of Life Aspects of Treatment, Care and Rehabilitation, 18, 873-880. doi:10.1007/s11136-009-9496-9

Hojat, M., Louis, D. Z., Maxwell, K., Markham, F., Wender, R., \& Gonnella, J. S. (2010). Patient perception of physician empathy, satisfaction with physician, interpersonal trust, and compliance. International Journal of Medical Education, 1, 83-87. doi:10.5116/ijme.4d00.b701

Hojat, M., Louis, D. Z., Maxwell, K., Markham, F., Wender, R., \& Gonnella, J. S. (2011). A brief instrument to measure patients' overall satisfaction with primary care physicians. Family Medicine, 43, 412-417.

Holmbeck, G. N. (2002). Post-hoc probing of significant moderational and mediational effects in studies of pediatric populations, Journal of Pediatric Psychology, 27, 8796, doi:10.1093/jpepsy/27.1.87 
Hossain F. (2020). Moral distress among healthcare providers and mistrust among patients during COVID-19 in Bangladesh. Developing World Bioethics, Advance online publication. doi:10.1111/dewb.12291

Idler, E. L., \& Benyamini, Y. (1997). Self-rated health and mortality: A review of twenty-seven community studies. Journal of Health and Social Behavior, 21-37.

Institute of Medicine. (2008). Health status and health care service. Utilization Committee on the Future Health Care Workforce for Older Americans, Retooling for an Aging America: Building the Health Care Workforce. National Academies Press.

Ionescu-Ittu, R., McCusker, J., Ciampi, A., Vadeboncoeur, A. M., Roberge, D., Larouche, D., Verdon, J., \& Pineault, R. (2007). Continuity of primary care and emergency department utilization among elderly people. CMAJ: Canadian Medical Association Journal, 177, 1362-1368. doi:10.1503/cmaj.061615

Islam, M. S., Sarkar, T., Khan, S. H., Mostofa Kamal, A. H., Hasan, S., Kabir, A....Seale, H. (2020). COVID-19 related Infodemic and its impact on public health: A global social media analysis. The American Journal of Tropical Medicine and Hygiene, 103, 16211629. doi:10.4269/ajtmh.20-0812

Jahn, S., Gauss, H. \& Kiessling, T. (2012). Trust, commitment, and older women: exploring brand attachment differences in the elderly segment. Psychology \& Marketing, 29, 445457.

Jain, S. H, Lucey, C., \& Crosson, F. J. (2020). The enduring importance of trust in the leadership of health care organizations. JAMA. 324, 2363-2364. doi:10.1001/jama.2020.18555

Jang, Y., Kim, G., \& Chiriboga, D. A. (2005). Health, healthcare utilization, and satisfaction with service: Barriers and facilitators for older Korean Americans. Journal of American 
Geriatric Society, 53, 1613-1617. doi:10.1111/j.1532-5415.2005.53518.x

Jenkinson, C., Coulter, A., Bruster, S., Richards, N., \& Chandola, T. (2002). Patients' experiences and satisfaction with health care: results of a questionnaire study of specific aspects of care. Quality \& Safety in Health Care, 11, 335-339. doi:10.1136/qhc.11.4.335

Jiang, M., Yang, G., Fang, L., Wan, J., Yang, Y., \& Wang, Y. (2018). Factors associated with healthcare utilization among community-dwelling elderly in Shanghai, China. PloS one, 13, e0207646. doi:10.1371/journal.pone.0207646

Jimmy, B., \& Jose, J. (2011). Patient medication adherence: measures in daily practice. Oman Medical Journal, 26, 155-159. doi:10.5001/omj.2011.38

Jin, H., Kim, Y., \& Rhie, S. J. (2016). Factors affecting medication adherence in elderly people. Patient Preference and Adherence, 10, 2117-2125. doi:10.2147/PPA.S118121

Julliard, K., Vivar, J., Delgardo, C., Cruz, E., Kabak, J., \& Sabers, H. (2008). What Latina patients don't tell their doctors: A qualitative study. Annals of Internal Medicine, 6, 543-549. doi:10.1370/afm.912

Jylhä, M. (2009). What is self-rated health and why does it predict mortality? Toward a unified conceptual model. Social Science and Medicine, 69, 307-316. doi:10.1016/j.socscimed.2009.05.013

Kao, A. C., Green, D. C., Zaslavsky, A. M., Koplan, J. P., \& Cleary, P. D. (1998). The relationship between method of physician payment and patient trust. JAMA. 280. 17081714. doi:10.1001/jama.280.19.1708

Kasturi, S., Szymonifka, J., Burket, J. C., Berman, J. R., Kirou, K. A., Levine, A. B., Sammaritano, L. R., \& Mandl, L. A. (2018). Feasibility, validity, and reliability of the 10- 
item Patient Reported Outcomes Measurement Information System Global Health Short Form in outpatients with systemic lupus erythematosus. The Journal of Rheumatology, 45, 397-404. doi:10.3899/jrheum.170590

Katzan, I. L., \& Lapin, B. (2018). PROMIS GH (Patient-Reported Outcomes Measurement Information System Global Health) Scale in stroke: A validation study. Stroke. 49, 147154. doi:10.1161/STROKEAHA.117.018766

Kawachi, I., Kennedy, B. P., Lochner, K. \& Prothrow-Stith, D. (1997). Social capital, income inequality and mortality. American Journal of Public Health, 87, 1491-1498.

Keating, N. L., Gandhi, T. K., Orav, E. J., Bates, D. W., \& Ayanian, J. Z. (2004). Patient characteristics and experiences associated with trust in specialist physicians. Archives of Internal Medicine, 164, 1015-1020. doi:10.1001/archinte.164.9.1015

Kim, A. M., Bae, J., Kang, S., Kim, Y., \& Lee, J. (2018). Patient factors that affect trust in physicians: A cross-sectional study. BMC Family Practice, 19, doi:10.1186/s12875-0180875-6

Kittleson, M. M. (2020). Trust in the time of COVID-19. The American Journal of Medicine, 133, 1370-1371. doi:10.1016/j.amjmed.2020.07.007

Kong, M. C., Camacho, F. T., Feldman, S. R., Anderson, R. T., \& Balkrishnan, R. (2007). Correlates of patient satisfaction with physician visit: differences between elderly and non-elderly survey respondents. Health and Quality of Life Outcomes, 5, 62-71. doi:10.1186/1477-7525-5-62

Köther, A. K., Siebenhaar, K. U., \& Alpers, G. W. (2021). Shared decision making during the COVID-19 pandemic. Medical Decision Making. 1-9. doi:10.1177/0272989X211004147

Kraetschmer, N., Sharpe, N., Urowitz, S,. \& Deber, R. B. (2004). How does trust affect patient 
preferences for participation in decision-making? Health Expect, 7, 317-326. doi:10.1111/j.1369-7625.2004.00296.x

Krot, K., \& Rudawska, I. (2017). Patients' trust in physicians as an antecedent of satisfaction with medical services. Economics and Sociology, 10, 207-216. doi:10.14254/2071789X.2017/10-2/15

Lam, K. H., \& Kwa, V. I. H. (2018). Validity of the PROMIS-10 Global Health assessed by telephone and on paper in minor stroke and transient ischaemic attack in the Netherlands. BMJ Open, 8, e019919. doi:10.1136/bmjopen-2017-019919

Lang, F. R., \& Carstensen, L. L. (2002). Time counts: Future time perspective, goals, and social relationships. Psychology and Aging, 17, 125-139. doi:10.1037/0882-7974.17.1.125

Lau, R. S., \& Cobb, A. T. (2010). Understanding the connections between relationship conflict and performance: The intervening roles of trust and exchange. Journal of Organisational Behaviour, 31, 898-917. doi:10.1002/job.674

LaVeist, T. A., Isaac, L. A., \& Williams, K. P. (2009). Mistrust of health care organizations is associated with underutilization of health services. Health Services Research, 44, 2093 2105. doi:10.1111/j.1475-6773.2009.01017.x

Lee, Y. Y., \& Lin, J. L. (2009). The effects of trust in physician on self-efficacy, adherence and diabetes outcomes. Social Science and Medicine, 68. 1060-1068. doi:10.1016/j.socscimed.2008.12.033

Lee, Y. Y., \& Lin, J. L. (2011). How much does trust really matter? A study of the longitudinal effects of trust and decision-making preferences on diabetic patient outcomes. Patient Education and Counseling, 85, 406-412. doi:10.1016/j.pec.2010.12.005

Legramante, J. M., Morciano, L., Lucaroni, F., Gilardi, F., Caredda, E., Pesaresi, A., ..... 
Palombi, L. (2016). Frequent use of emergency departments by the elderly population ehen continuing care is not well established. PloS one, 11, e0165939. doi:10.1371/journal.pone.0165939

Levinson, W., Kao, A., Kuby, A., \& Thisted, R. A. (2005). Not all patients want to participate in decision making. A national study of public preferences. Journal of General Internal Medicine, 20, 531-535. doi:10.1111/j.1525-1497.2005.04101.x

Lewicki, R. J., \& Bunker, B. B. (1996). Developing and maintaining trust in work relationships. In R. M.Kramer \& T. R. Tyler (Eds.), Trust in organizations, frontiers of theory and research. Sage Publications.

Lewicki, R. J., Tomlinson, E. C., and Gillespie, N. (2006). Models of interpersonal trust development: Theoretical approaches, empirical evidence, and future directions. Journal of Management, 32. 991-1022. doi:10.1177/0149206306294405

Li, T., \& Fung, H. H. (2013). Age differences in trust: An investigation across 38 countries, The Journals of Gerontology: Series B, 68, 347-355. doi:10.1093/geronb/gbs072

Ling, B. S., Klein, W. M., \& Dang, Q. (2006). Relationship of communication and information measures to colorectal cancer screening utilization: Results from HINTS. Journal of Health Communication, 11, 181-190. doi:10.1080/10810730600639190.

Löckenhoff, C. E., \& Carstensen, L. L. (2007). Aging, emotion, and health-related decision strategies: motivational manipulations can reduce age differences. Psychology and Aging, 22, 134-146. doi:10.1037/0882-7974.22.1.13

Löckenhoff, C. E., \& Carstensen, L. L. (2008). Decision strategies in health care choices for self and others: older but not younger adults make adjustments for the age of the decision target. The Journals of Gerontology. Series B, Psychological Sciences and Social 
Sciences, 63, P106-P109. doi:10.1093/geronb/63.2.p106

Loomba, S., de Figueiredo, A., Piatek, S.J. (2021). Measuring the impact of COVID-19 vaccine misinformation on vaccination intent in the UK and USA. Nature Human Behavior, 5, 337-348. doi:10.1038/s41562-021-01056-1

Lutomski, J. E., Baars, M. A., Schalk, B.W., Boter, H., Buurman, B. M., den Elzen, W. P.... \& TOPICS-MDS Consortium. (2013). The development of the Older Persons and Informal Caregivers Survey Minimum DataSet (TOPICS-MDS): A large-scale data sharing initiative. PloS One, 8, e81673. doi:10.1371/journal.pone.0081673

Lynch, S. M. (2003). Cohort and life-course patterns in the relationship between education and health: A hierarchical approach. Demography, 40, 309-331. doi:10.1353/dem.2003.0016.

Mainous, A. G., Baker, R., Periera Gray, D., \& Gill, J. M. R. (2001). Continuity of care and trust in one's physician: Evidence from primary care in the United States and the United Kingdom. Family Medicine, 33, 22-27.

Martin, L. R., Williams, S. L., Haskard, K. B., \& Dimatteo, M. R. (2005). The challenge of patient adherence. Therapeutics and Clinical Risk Management, 1, 189-199.

Mason, W. \& Suri, S. (2012). Conducting behavioral research on Amazon's Mechanical Turk. Behavior Research Methods, 44, 1-23. doi:10.3758/s13428-011-0124-6

Mayer, R. C., Davis, J. H., \& Schoorman, F. D. (1995). An integrative model of organizational trust. The Academy of Management Review, 20, 709-734.

McCusker, J., Karp, I., Cardin, S., Durand, P., \& Morin, J. (2003). Determinants of emergency department visits by older adults: A systematic review. Academic Emergency Medicine, 10, 1362-1370. doi:10.1111/j.1553-2712.2003.tb00011.x.

Mechanic, D. (1996). Changing medical organization and the erosion of trust. The Milbank 
Quarterly, 74, 171-189. doi:10.2307/3350245

Mishra, A. K. (1996). Organizational responses to crisis: The centrality of trust. In R. M. Kramer \& T. Tyler (Ed.), Trust in Organizations. (pp. 261-287). Sage Publications.

Mollborn, S., Stepanikova, I., \& Cook, K. S. (2005). Delayed care and unmet needs among health care system users: When does fiduciary trust in a physician matter? Health Services Research, 40, 1898-1917. doi:10.1111/j.1475-6773.2005.00457.x

Mohseni, M., \& Lindstrom, M. (2006). Social capital, trust in the health-care system and selfrated health: The role of access to health care in a population-based study. Social Sciences and Medicine, 64. 1373-1383. doi:10.1016/j.socscimed.2006.11.023

Montori, V. M., Gafni, A., \& Charles, C. (2006). A shared treatment decision-making approach between patients with chronic conditions and their clinicians: The case of diabetes. Health Expectations, 9. 25-36.

Musa, D., Schultz, R., Harris, R., Silverman, M., \& Thomas, S. B. (2009). Trust in the health care system and the use of preventive health services by older black and white adults. American Journal of Public Health, 99, 1293-1299. doi:10.2105/AJPH.2007.123927

Nguyen, G. C., LaVeist, T. A., Harris, M. L., Datta, L. W., Bayless, T. M., \& Brant, S. R. (2009). Patient trust-in-physician and race are predictors of adherence to medical management in inflammatory bowel disease. Inflammatory Bowel Diseases, 15, 12331239. doi:10.1002/ibd.20883

Naeem, S. B., Bhatti, R., \& Khan, A. (2020). An exploration of how fake news is taking over social media and putting public health at risk. Health Information and Libraries Journal, 10.1111/hir.12320. Advance online publication. doi:10.1111/hir.12320

Naik, A. D., Street, R. L., Jr, Castillo, D., \& Abraham, N. S. (2011). Health literacy and decision 
making styles for complex antithrombotic therapy among older multimorbid adults. Patient Education and Counseling, 85, 499-504. doi:10.1016/j.pec.2010.12.015

Nie, J. X., Wang, L., Tracy, C. S., Moineddin, R., \& Upshur, R. E. (2010). A population-based cohort study of ambulatory care service utilization among older adults. Journal of Evaluation in Clinical Practice, 16, 825-831. doi:10.1111/j.1365-2753.2009.01218.x

Nooteboom, B. (2002). Trust: Forms, foundations, functions, failures and figures. Cheltenham: Edward, Elgar.

Nutting, P. A., Goodwin, M. A., Flocke, S. A., Zyzanski, S. J., \& Stange, K. C. (2003). Continuity of primary care: To whom does it matter and when?. Annals of Family Medicine, 1, 149-155. doi:10.1370/afm.63

O’Malley, A. S., Sheppard, V. B., Schwartz, M., \& Mandelblatt, J. (2004). The role of trust in use of preventive services among low-income African American women. Preventive Medicine, 38, 777-785. doi:10.1016/j.ypmed.2004.01.018

Ommen, O., Thuem, S., Pfaff, H., \& Janssen, C. (2011). The relationship between social support, shared decision-making and patient's trust in doctors: A cross-sectional survey of 2,197 inpatients using the Cologne Patient Questionnaire. International Journal of Public Health, 56. 319-327. doi:10.1007/s00038-010-0212-x

Oppenheimer, D. M., Meyvis, T., \& Davidenko, N. (2009). Instructional manipulation checks: Detecting satisficing to increase statistical power. Journal of Experimental Social Psychology, 45. 867-872. doi:10.1017/j.jesp.2009.03.009

Ozawa, S. (2008). The role of trust in health care systems: Does trust matter? Oxford Policy Institute: Oxford.

Ozawa, S., \& Sripad, P. (2013) How do you measure trust in the health system? A systematic 
review of the literature. Social Science \& Medicine, 91, 10-14.

doi:10.1016/j.socscimed.2013.05.005

Ozawa, S., Paina, L. \& Qiu, M. (2016). Exploring pathways for building trust in vaccination and strengthening health system resilience. BMC Health Services Research, 16. 131-141. doi:10.1186/s12913-016-1867-7

Palmer, R. C., Midgette, L. A., \& Dankwa, I. (2008). Colorectal cancer screening and African Americans: Findings from a qualitative study. Cancer Control, 15, 72-79. doi:10.1177/107327480801500109.

Pampel, F. C., Krueger, P. M., \& Denney, J. T. (2010). Socioeconomic disparities in health behaviors. Annual Review of Sociology, 36, 349-370.

doi:10.1146/annurev.soc.012809.102529

Paolacci, G., \& Chandler, J. (2014). Inside the turk: Understanding Mechanical Turk as a participant pool. Current Directions in Psychological Science, 23, 184-188. doi:10.1177/0963721414531598

Pearson, S. \& Raeke, L. (2000). Patients' trust in physicians: Many theories, few measures, and little data. Journal of General Internal Medicine. 15, 509-513. doi:10.1046/j.1525-1497.2000.11002.x

Peck, B. (2011). Age-related differences in doctor-patient interaction and patient satisfaction. Current Gerontology and Geriatrics Research, Article 13749. doi:10.1155/2011/137492

Phimmasane, M., Douangmala, S., Koffi, P., Reinharz D., \& Buisson, Y. (2010). Factors affecting compliance with measles vaccination in Lao PDR. Vaccine, 28, 6723-6729. doi:10.1016/j.vaccine.2010.07.077

Piette, J. D., Heisler, M., Krein, S., \& Kerr, E. A. (2005). The role of patient-physician trust in 
moderating medication nonadherence due to cost pressures. Archives of Internal Medicine, 165. doi:10.1001/archinte.165.15.1749

Pinder, R. J., Ferguson, J., \& Møller, H. (2016). Minority ethnicity patient satisfaction and experience: Results of the National Cancer Patient Experience Survey in England. BMJ Open, 6, e011938. doi:10.1136/bmjopen-2016-011938

Platonova, E. A., Kennedy, K. N. \& Shewchuk, R. M. (2008). Understanding patient satisfaction, trust, and loyalty to primary care physicians. Medical Care Research and Review, 65, 696-712. doi:10.1177/1077558708322863

Polinski, J. M., Kesselheim, A. S., Frolkis, J. P., Wescott, P., Allen-Coleman, C., \& Fischer, M. A. (2014). A matter of trust: patient barriers to primary medication adherence. Health Education Research, 29, 755-63. doi:10.1093/her/cyu023

Poulin, M. J., \& Haase, C. M. (2015). Growing to trust: Evidence that trust increases and sustains well-being across the life span. Social Psychological and Personality Science, 6, 614621. doi:10.1177/1948550615574301

Razai, M. S., Osama, T., McKechnie, D. G. J., \& Majeed, A. (2021). Covid-19 vaccine hesitancy among ethnic minority groups. $B M J, 372,513-521$. doi:10.1136/bmj.n513

Ritter, P. L., Stewart, A. L., Kaymaz, H., Sobel, D. S., Block, D. A., \& Lorig, K. R. (2001). Selfreports of health care utilization compared to provider records. Journal of Clinical Epidemiology, 54, 136-141. doi:10.1016/s0895-4356(00)00261-4

Rocque, R., \& Leanza, Y. (2015). A systematic review of patients' experiences in communicating with primary care physicians: Intercultural encounters and a balance between vulnerability and integrity. PloS one, 1, e0139577. doi:10.1371/journal.pone.0139577 
Rodríguez, V., Andrade, A. D., García-Retamero, R., Anam, R., Rodríguez, R., Lisigurski, M.... Ruiz, J. G. (2013) Health literacy, numeracy, and graphical literacy among veterans in primary care and their effect on shared decision making and trust in physicians. Journal of Health Communication, 18, 273-289, doi:10.1080/10810730.2013.829137

Rose, A., Peters, N., Shea, J. A., \& Armstrong, K. (2004). Development and testing of the health care system distrust scale. Journal of General Internal Medicine, 19, 57-63. doi:10.1111/j.1525-1497.2004.21146.x

Rutter, H., Wolpert, M., \& Greenhalgh, T. (2020). Managing uncertainty in the Covid-19 era. BMJ, 370, e3349. doi:10.1136/bmj.m3349

Safran, D., Kosinski, M., Tarlov, A., Rogers, W., Taira, D., Lieverman, N., \& Ware, J. (1998) The Primary Care Assessment Survey: Tests of data quality and measurement performance. Medical Care, 36, 728-739.

Salkeld, G., Solomon, M., Short, L., \& Butow, P. N. (2004). A matter of trust-patient's views on decision-making in colorectal cancer. Health Expect, 7, 104-114. doi:10.1111/j.13697625.2004.00257.x

Schattner, A., Bronstein, A., \& Jellin, N. (2006). Information and shared decision-making are top patients' priorities. BMC Health Services Research, 6, 21-27. doi:10.1186/1472-6963-621

Schellekens, J., \& Ziv, A. (2020). The role of education in explaining trends in self-rated health in the United States, 1972-2018. Demographic Research, 42, 383-398. doi:10.2307/26936792

Schneider, A., Körner, T., Mehring, M., Wensing, M., Elwyn, G., \& Szecsenyi, J. (2006). Impact of age, health locus of control and psychological co-morbidity on patients' preferences for shared decision making in general practice. Patient Education and Counseling, 61, 292- 
298. doi:10.1016/j.pec.2005.04.008.

Sepucha, K. R., Fagerlin, A., Couper, M. P., Levin, C.A., Singer, E., \& Zikmund-Fisher, B. J. (2010). How does feeling informed relate to being informed? The DECISIONS survey. Medical Decision Making, 30.77S-84S. doi:10.1177/0272989X10379647

Shan, L., Li, Y., Ding, D., Wu, Q., Liu, C., Jiao, M....Ren, J. (2016). Patient satisfaction with hospital inpatient care: Effects of trust, medical insurance and perceived quality of care. PloS One, 11, e0164366.doi:10.1371/journal.pone.0164366

Shea, J. A., Micco, E., Dean, L. T., McMurphy, S., Schwartz, J. S., \& Armstrong, K. (2008). Development of a revised Health Care System Distrust scale. Journal of General Internal Medicine, 23, 727-732. doi:10.1007/s11606-008-0575-3

Shenolikar, R. A., Balkrishnan, R., \& Hall, M. A. (2004). How patient-physician encounters in critical medical situations affect trust: Results of a national survey. BMC Health Services Research, 4, 1-6. doi:10.1186/1472-6963-4-24

Short, M. E., Goetzel, R. Z., Pei, X., Tabrizi, M. J., Ozminkowski, R. J., Gibson, T. B....Wilson, M. G. (2009). How accurate are self-reports? Analysis of self-reported health care utilization and absence when compared with administrative data. Journal of Occupational and Environmental Medicine, 51, 786-796. doi:10.1097/JOM.0b013e3181a86671

Siegrist, M., \& Zingg, A. (2014). The role of public trust during pandemics: Implications for crisis communication. European Psychologist, 19, 23-32. doi:10.1027/1016$9040 / \mathrm{a} 000169$

Simon, M. A., Zhang, M., \& Dong, X. (2014). Trust in physicians among U.S. Chinese older adults. The Journals of Gerontology: Series A, 69, S4-S53. doi:10.1093/gerona/glu174 
Six, F. E. (2007). Building interpersonal trust within organizations: A relational signalling perspective. Journal of Management and Governance, 11, 285-309. doi:10.1007/s10997-007-9030-9

Smith, C. P. (2017). First, do no harm: institutional betrayal and trust in health care organizations. Journal of Multidisciplinary Healthcare, 10, 133-144. doi:10.2147/JMDH.S125885

Soril, L. J., Leggett, L. E., Lorenzetti, D. L., Noseworthy, T. W., \& Clement, F. M. (2016). Characteristics of frequent users of the emergency department in the general adult population: A systematic review of international healthcare systems. Health Policy, 120, 452-461. doi:10.1016/j.healthpol.2016.02.006

Stacey, D., Legara, N., Cl, B., Mj, B., Kb, E., ...Holmes-rovner, M. (2014). Decision aids for people facing health treatment or screening decisions. The Cochrane Database of Systematic Reviews. 4. CD001431. doi:10.1002/14651858.CD001431.pub4.Copyright

Stroud, C., Walker, L. R., Davis, M., \& Irwin, C. E. Jr. (2015). Investing in the health and wellbeing of young adults. Journal of Adolescent Health, 56, 127-129. doi:10.1016/j.jadohealth.2014.11.012

Taha, S. A., Matheson, K., \& Anisman, H. (2013) The 2009 H1N1 Influenza pandemic: The role of threat, coping, and media trust on vaccination intentions in Canada. Journal of Health Communication, 18, 278-290, doi:10.1080/10810730.2012.727960

Tam, W. (2012). Health care reform and patients' trust in physicians in urban Beijing. The China Quarterly, 211.827-843.

Tan, H., \& Lim, A. (2009). Trust in co-workers and trust in organisations. The Journal of Psychology, 143, 45-66. doi:10.3200/JRLP.143.1.45-66 
Tang, L. (2011). The influences of patient's trust in medical service and attitude towards health policy on patient's overall satisfaction with medical service and sub satisfaction in China. BMC Public Health, 11, 472-480. doi:10.1186/1471-2458-11-472

Tang, F., Liang, J., Zhang, H., Kelifa, M. M., He, Q., \& Wang, P. (2020). COVID-19 related depression and anxiety among quarantined respondents. Psychology \& Health, 1-15. doi: $10.1080 / 08870446.2020 .1782410$

Thom, D., Hall, M. A. \& Pawlson, G. L. (2004). Measuring patients' trust in physicians when assessing quality of care. Health Affairs. 23, 124-132. doi:10.1377/hlthaff.23.4.124.

Thom, D. H., Kravitz, R. L., Bell, R. A., Krupat, E., \& Azari, R. (2002). Patient trust in the physician: Relationship to patient requests. Family Practice, 19, 476-483. doi:10.1093/fampra/19.5.476

Torbit, L. A., Albiani, J. J., Aronson, M., Holter, S., Semotiuk, K.,....Hart, T. L. (2016). Physician trust moderates the relationship between intolerance of uncertainty and cancer worry interference among women with Lynch syndrome. Journal of Behavioral Medicine, 29, 420-428. doi:10.1007/s10865-016-9711-4

Trachtenberg, F., Dugan, E., \& Hall, M. A. (2005). How patients' trust relates to their involvement in medical care. The Journal of Family Practice. 54, 344-352.

Traylor, A. H., Schmittdiel, J. A., Uratsu, C. S., Mangione, C. M., \& Subramanian, U. (2010). Adherence to cardiovascular disease medications: Does patient-provider race/ethnicity and language concordance matter?. Journal of General Internal Medicine, 25, 11721177. doi:10.1007/s11606-010-1424-8

Trust. (n.d.). https://www.merriam-webster.com/dictionary/trust.

Tsai, T., Yu, W., \& Lee, S. (2018). Is health literacy associated with greater medical care 
trust? International Journal for Quality in Health Care, 30, 514-519.

doi:10.1093/intqhe/mzy043. PMID: 29608676.

U.S. Census Bureau (2018). Older people projected to outnumber children for first time in U.S. history. https://www.census.gov/newsroom/press-releases/2018/cb18-41-populationprojections.html

U.S. Census Bureau (2020). Population Estimates Quick Facts Table 2020. https://www.census.gov/quickfacts/fact/table/US/PST045219

van Dalen, M. T., Suijker, J. J., MacNeil-Vroomen, J., van Rijn, M., Moll van Charante, E. P., \& de Rooij, S. E. (2014) Self-report of healthcare utilization among community-dwelling older persons: A prospective cohort study. PLoS ONE, 9. 933-972. doi:10.1371/journal.pone.0093372

van Loenen, T., van den Berg, M. J., Westert, G. P., \& Faber, M. J. (2014). Organizational aspects of primary care related to avoidable hospitalization: A systematic review. Family Practice, 31, 502-16. doi:10.1093/fampra/cmu053

Vinck, P., Pham, P., Bungu, K., Bedford, J., \& Nilles, E. (2019). Institutional trust and misinformation in the response to the 2018-19 Ebola outbreak in North Kivu, DR Congo: a population-based survey. The Lancet Infectious Diseases, 19, 529-536

Wamala, S., Merlo, J., Bostrom, G., Hogstedt, C., \& Agren, G. (2007). Socioeconomic disadvantage and primary non-adherence with medication in Sweden. International Journal for Quality in Health Care, 19, 134-40. doi:10.1093/intqhe/mzm011.

Ward, P. R., Meyer, S. B., Verity, F., Gill, T. K., \& Luong, T. C. (2011). Complex problems require complex solutions: The utility of social quality theory for addressing the social determinants of health. BMC Public Health, 11, 630-642. doi:10.1186/1471-2458-11- 
630

Ward, P. R., Rokkas, P., Cenko, C., Pulvirenti, M., Dean, N., Carney, S.,.... Meyer, S. (2015). A qualitative study of patient (dis)trust in public and private hospitals: The importance of choice and pragmatic acceptance for trust considerations in South Australia. BMC Health Services Research, 15, 297-305. doi:10.1186/s12913-015-0967-0

Weng, H. C. (2008). Does the physician's emotional intelligence matter? Impacts of physician's emotional intelligence on trust, patient-physician relationship, and satisfaction. Health Care Management Review, 33, 280-288. doi:10.1097/01.HCM.0000318765.52148.b3

Whetten, K., Leserman, J., Whetten, R., Ostermann, J., Thielman, N.,....Stangl, D. (2006). Exploring lack of trust in care providers and the government as a barrier to health service use. American Journal of Public Health, 96, 716-721. doi:10.2105/AJPH.2005.063255

Wilson, S. L., \& Wiysonge, C. (2020). Social media and vaccine hesitancy, BMJ Global Health, $5, \mathrm{e} 004206$

World Health Organization. (2020). Managing the COVID-19 infodemic: Promoting healthy behaviours and mitigating the harm from misinformation and disinformation. https://www.who.int/news/item/23-09-2020-managing-the-covid-19-infodemicpromoting-healthy-behaviours-and-mitigating-the-harm-from-misinformation-anddisinformation

Worrall, G., \& Knight, J. (2006). Continuity of care for older patients in family practice: How important is it?. Canadian Family Physician, 52, 754-755.

Xie, Z., St Clair, P., Goldman, D. P., \& Joyce, G. (2019). Racial and ethnic disparities in medication adherence among privately insured patients in the United States. PloS one, 14, e0212117. doi:10.1371/journal.pone.0212117 
Zajacova, A., \& Dowd, J. B. (2011). Reliability of self-rated health in US adults. American Journal of Epidemiology, 174, 977-983. doi:10.1093/aje/kwr204

Zebrowitz, L. A., Boshyan, J., Ward, N., Gutchess, A., \& Hadjikhani, N. (2017). The older adult positivity effect in evaluations of trustworthiness: Emotion regulation or cognitive capacity?. PloS One, 12, e0169823. doi:10.1371/journal.pone.0169823

Zebrowitz, L. A., Franklin, R. G., Hillman, S., \& Boc, H. (2013). Older and younger adults' first impressions from faces: Similar in agreement but different in positivity. Psychology and Aging, 28, 202-212. doi:10.1037/a0030927

Zhao, G., Okoro, C. A., Hsia, J., \& Town, M. (2018). Self-perceived poor/fair health, frequent mental distress, and health insurance status among working-aged US adults. Preventing Chronic Disease, 15, e95. doi:10.5888/pcd15.170523

Zheng, B., Hall, M.A., Dugan, E., Kidd, K. E., \& Levine, D. (2002). Development of a scale to measure patients' trust in health insurers. Health Services Research, 37, 185-200. doi:10.1111/1475-6773.00145

Zolnierek, K. B., \& Dimatteo, M. R. (2009). Physician communication and patient adherence to treatment: A meta-analysis. Medical Care, 47, 826-834. doi:10.1097/MLR.0b013e31819a5acc 
Table 1

Demographic Information $(N=398)$

\begin{tabular}{lcr}
\hline Characteristic & $N$ & $\% / \mathrm{SD}$ \\
\hline Age (M) & 52.43 & 17.18
\end{tabular}

Gender

Female

Male

Race/ethnicity

White/Caucasian (not Hispanic)

Black/African-American

Asian-American

Hispanic

Native American/Pacific Islander

Bi-racial/ Mixed Race

Not Reported

\section{Marital Status}

Single

Married/Committed Relationship

Divorced

Separated

Widowed
162

236

$40.7 \%$

$59.3 \%$

$60.6 \%$

38

$9.5 \%$

71

$17.8 \%$

25

$6.3 \%$

9

$2.3 \%$

4

$1.0 \%$

10

$2.5 \%$

45

$11.3 \%$

345

$86.7 \%$

5

2

1
$1.3 \%$

$0.5 \%$

$0.3 \%$

\section{Number of Chronic Conditions}

None

One
114

178
$28.6 \%$

$44.7 \%$ 
Two

Three

Four

Five

Diagnosed with COVID-19

Yes

No

Not Reported
74

20

3

9
$18.6 \%$

$5.0 \%$

$0.8 \%$

$2.3 \%$

$95 \quad 23.9 \%$

$302 \quad 75.9 \%$

$1 \quad .02 \%$


Table 2

Correlations between participant characteristics and variables

\begin{tabular}{|c|c|c|c|c|c|c|c|c|c|c|c|c|c|}
\hline & Age & Education & $\mathrm{CHC}$ & COVID-19** & ** WFPTS & HCSTS & PROMIS & HCU_D & HCU_E & HCU_HA & PDSM & Adher. & HCSQ \\
\hline Age & 1 & .010 & $.116^{*}$ & -.002 & .016 & $.110^{*}$ & .000 & $.265 * *$ & $.204 * *$ & $.231 * *$ & $.137 * *$ & .077 & .072 \\
\hline Education & .010 & 1 & -.019 & $-.157 * *$ & $.174 * *$ & .057 & $.110 *$ & -.012 & -.067 & -.051 & -.029 & $.171 * *$ & $.167 * *$ \\
\hline $\mathrm{CHC}$ & $.116^{*}$ & -.019 & 1 & $.232 * *$ & .014 & .015 & $-.098^{*}$ & $.170 * *$ & $.146^{* *}$ & $.116^{* *}$ & .021 & -.068 & -.014 \\
\hline COVID-19 & .002 & $-.157 * *$ & $.232 * *$ & 1 & -.018 & $-.148 * *$ & -.010 & $.227 * *$ & $.218^{* *}$ & $.219 * *$ & $.124 * *$ & .054 & .062 \\
\hline WFPTS & .016 & $.174 * *$ & .014 & -.018 & 1 & $.380 * *$ & $.312 * *$ & -.054 & $-.155^{* *}$ & $-.141 * *$ & $-.278 * *$ & $.389 * *$ & $.554 * *$ \\
\hline HCSTS & $.110 *$ & .057 & .015 & $-.148 * *$ & $.380 * *$ & 1 & -.062 & $-.319 * *$ & $-.402 * *$ & $-.354 * *$ & $-.460 * *$ & .081 & $.257 * *$ \\
\hline PROMIS & .000 & $.110 *$ & $-.098 *$ & -.010 & $.312 * *$ & -.062 & 1 & $.220 * *$ & $288 * *$ & $.296 * *$ & $.362 * *$ & $.403 * *$ & $.586 * *$ \\
\hline HCU_DV & $.265^{* *}$ & -.012 & $.170 * *$ & $.227 * *$ & -.054 & $-.319 * *$ & $.220 * *$ & 1 & $.788 * *$ & $.809 * *$ & $.562 * *$ & $.201 * *$ & $.247 * *$ \\
\hline HCU_ER & $.204 * *$ & -.067 & $.146^{* *}$ & $.218 * *$ & $-.155 * *$ & $-.402 * *$ & $.288 * *$ & $.788 * *$ & 1 & $.864 * *$ & $.697 * *$ & $.099 *$ & $.239 * *$ \\
\hline HCU_HA & $.231 * *$ & -.051 & $.116^{*}$ & $.219 * *$ & $-.141 * *$ & $-.354 * *$ & $.296 * *$ & $.809 * *$ & $.864 * *$ & 1 & $.699 * *$ & $.115^{*}$ & $244 * *$ \\
\hline PDSM & $.137 * *$ & -.029 & .021 & $.124 *$ & $-.278 * *$ & $-.460 * *$ & $.362 * *$ & $.562 * *$ & $.697 * *$ & $.699 * *$ & 1 & -.054 & $.267 * *$ \\
\hline Adher. & .077 & $.171 * *$ & -.068 & .054 & $.389 * *$ & .081 & $.403 * *$ & $.201 * *$ & $.099 *$ & $.115 *$ & -.054 & 1 & $.494 * *$ \\
\hline HCSQ & .072 & $.167 * *$ & -.014 & .062 & $.554^{* *}$ & $.257 * *$ & $.586^{* *}$ & $.247 * *$ & $.239 * *$ & $.244 * *$ & $.267 * *$ & $.494^{* *}$ & 1 \\
\hline
\end{tabular}

Note. ${ }^{* * *}$. Point biserial correlations were run for the COVID-19 variable **. $p<.01$ (2-tailed) ${ }^{*} p<.05$ (2-tailed)

$\mathrm{CHC}=$ Chronic health conditions

COVID-19 = Diagnosed with coronavirus or not WFPTS $=$ Wake Forest Physician Trust Scale HCSTS = Health Care System Trust Scale

PROMIS = Patient-Report Outcomes Measurement Information System 10 Global Health Scale HCU_DV $=$ Healthcare Utilization of Services- Doctors' Visits

HCU_ER = Healthcare Utilization of Services- ER Visits

HCU_HA = Healthcare Utilization of Services- Hospital Admissions

PDSM = Problem-Solving Decision-Making Scale

Adher. = Adherence Measure

HCSQ = Health Care Satisfaction Questionnaire 
Table 3

Means and standard deviations for key study variables

\begin{tabular}{lccc}
\hline Variable & Respondents' score range & $M$ & $S D$ \\
\hline Trust in Physician (WFPTS) & $10-50$ & 34.52 & 4.74 \\
Trust in Healthcare System (HCSTS) & $9-45$ & 26.96 & 3.62 \\
Self-Rated Health (PROMIS) & $10-40$ & 36.35 & 5.46 \\
Healthcare Utilization- Doctors' Visits & $1-10$ & 5.69 & 2.71 \\
Healthcare Utilization- ER Visits & $1-10$ & 4.99 & 3.31 \\
Healthcare Utilization- Hospital Admits & $1-10$ & 5.13 & 3.34 \\
Preference for Decision-Making (PDSM) & $1-5$ & 3.33 & 0.77 \\
Adherence & $1-5$ & 3.90 & 0.69 \\
Patient Satisfaction (HCSQ) & $23-92$ & 67.66 & 9.18
\end{tabular}


Table 4

Moderation Analysis: Results of Age X Health Outcome Variables for Trust in Physicians

\begin{tabular}{|c|c|c|c|c|}
\hline Model & Variables Entered and Interactions & $b$ & $S E$ & $p$ \\
\hline \multirow[t]{3}{*}{1.} & Constant (Self-Rated Health) & 36.6529 & 1.3052 & .0000 \\
\hline & Trust in Physicians & .3501 & .0553 & .0000 \\
\hline & Age & .0017 & .0153 & .9100 \\
\hline 2. & Trust in Physicians x Age & -.0058 & .0031 & .0586 \\
\hline \multicolumn{5}{|c|}{$R^{2}=.1210$} \\
\hline \multirow[t]{3}{*}{1.} & Constant (HCU- Doctor's Visits) & 4.8366 & .4423 & .0000 \\
\hline & Trust in Physicians & -.0354 & .0281 & .2088 \\
\hline & Age & .0428 & .0078 & .0000 \\
\hline 2. & Trust in Physicians x Age & -.0024 & .0015 & .1287 \\
\hline \multicolumn{5}{|c|}{$R^{2}=.1536$} \\
\hline \multirow[t]{3}{*}{1.} & Constant (HCU- ER Visits) & 4.3218 & .5430 & .0000 \\
\hline & Trust in Physicians & -.1064 & .0345 & .0022 \\
\hline & Age & .0388 & .0096 & .0001 \\
\hline 2. & Trust in Physicians x Age & -.0017 & .0019 & .3766 \\
\hline \multicolumn{5}{|c|}{$R^{2}=.1250$} \\
\hline \multirow[t]{3}{*}{1.} & Constant (HCU- Hospital Admissions) & 4.2879 & .5452 & .0000 \\
\hline & Trust in Physicians & -.1074 & .0347 & .0021 \\
\hline & Age & .0453 & .0096 & .0000 \\
\hline 2. & Trust in Physicians x Age & -.0047 & .0019 & .0151 \\
\hline \multicolumn{5}{|c|}{$R^{2}=.1473$} \\
\hline \multirow[t]{2}{*}{1.} & Constant (Decision-Making) & 3.1682 & .1276 & .0000 \\
\hline & Trust in Physicians & -.0463 & .0081 & .0000 \\
\hline
\end{tabular}


$\begin{array}{llll}\text { Age } & .0067 & .0023 & .0031\end{array}$

$\begin{array}{lllll}\text { 2. Trust in Physicians x Age } & -.0006 & .0004 & .1848\end{array}$

$R^{2}=.1195$

\begin{tabular}{llll}
\hline $1 . \quad$ Constant (Adherence) & 3.6472 & .1097 & .0000 \\
Trust in Physicians & .0530 & .0070 & .0000 \\
Age & .0033 & .0019 & .0909 \\
$R^{2}=.1938$ & -.0003 & .0004 & .3859 \\
\hline Trust in Physicians x Age & & & \\
$\quad$ Constant (Patient Satisfaction) & 64.8723 & 1.3032 & .0000 \\
$\quad$ Trust in Physicians & .9972 & .0829 & .0000 \\
$\quad$ Age & .0388 & .0230 & .0928 \\
$\quad$ Trust in Physicians x Age & -.0150 & .0046 & .0011 \\
$R^{2}=.3440$ & & &
\end{tabular}

HCU $=$ Healthcare Utilization of Services 
Table 5

Moderation Analysis: Results of Age X Health Outcome Variables for Trust in the Healthcare System

\begin{tabular}{|c|c|c|c|c|}
\hline Model & Variables Entered and Interactions & $b$ & $S E$ & $p$ \\
\hline \multirow[t]{3}{*}{1.} & Constant (Self-Rated Health) & 34.6957 & .9505 & .0000 \\
\hline & Trust in Healthcare System & -.0746 & .0813 & .3593 \\
\hline & Age & .0074 & .0170 & .6653 \\
\hline 2. & Trust in Healthcare System x Age & -.0046 & .0043 & .2857 \\
\hline \multicolumn{5}{|c|}{$R^{2}=.0373$} \\
\hline \multirow[t]{3}{*}{$\overline{1 .}$} & Constant (HCU- Doctor's Visits) & 4.7766 & .4292 & .0000 \\
\hline & Trust in Healthcare System & -.1940 & .0367 & .0000 \\
\hline & Age & .0396 & .0077 & .0000 \\
\hline 2. & Trust in Healthcare System x Age & -.0036 & .0020 & .0659 \\
\hline \multicolumn{5}{|c|}{$R^{2}=.2094$} \\
\hline \multirow[t]{3}{*}{1.} & Constant (HCU- ER Visits) & 4.4630 & .5168 & .0000 \\
\hline & Trust in Healthcare System & -.3196 & .0442 & .0000 \\
\hline & Age & .0318 & .0092 & .0006 \\
\hline 2. & Trust in Healthcare System x Age & -.0023 & .0023 & .3357 \\
\hline \multicolumn{5}{|c|}{$R^{2}=.2138$} \\
\hline \multirow[t]{3}{*}{$\overline{1 .}$} & Constant (HCU- Hospital Admissions) & 4.4156 & .5328 & .0000 \\
\hline & Trust in Healthcare System & -.2722 & .0456 & .0000 \\
\hline & Age & .0390 & .0095 & .0001 \\
\hline 2. & Trust in Healthcare System x Age & -.0024 & .0024 & .2194 \\
\hline \multicolumn{5}{|c|}{$R^{2}=.1923$} \\
\hline \multirow[t]{2}{*}{1.} & Constant (Decision-Making) & 3.2208 & .1204 & .0000 \\
\hline & Trust in Healthcare System & -.0945 & .0103 & .0000 \\
\hline
\end{tabular}




$$
\begin{array}{llll}
\text { Age } & .0049 & .0022 & .0237
\end{array}
$$

$\begin{array}{llll}\text { 2. Trust in Healthcare System x Age } & -.0012 & .0005 & .0237\end{array}$

$$
R^{2}=.2219
$$

\begin{tabular}{llll}
\hline $1 . \quad$ Constant (Adherence) & 3.5409 & .1181 & .0000 \\
Trust in Healthcare System & .0198 & .0101 & .0503 \\
Age & .0037 & .0021 & .0780 \\
$2 . \quad$ Trust in Healthcare System x Age & .0002 & .0005 & .6962 \\
$R^{2}=.0727$ & & & \\
\hline $1 . \quad$ & 62.3828 & 1.5562 & .0000 \\
$\quad$ Constant (Patient Satisfaction) & .2875 & .1331 & .0314 \\
$\quad$ Trust in Healthcare System & .0506 & .0278 & .0654 \\
$\quad$ Age & -.0088 & .0071 & .2133 \\
Trust in Healthcare System x Age & & & \\
$R^{2}=.0722$ & & &
\end{tabular}

$\mathrm{HCU}=$ Healthcare Utilization of Services 


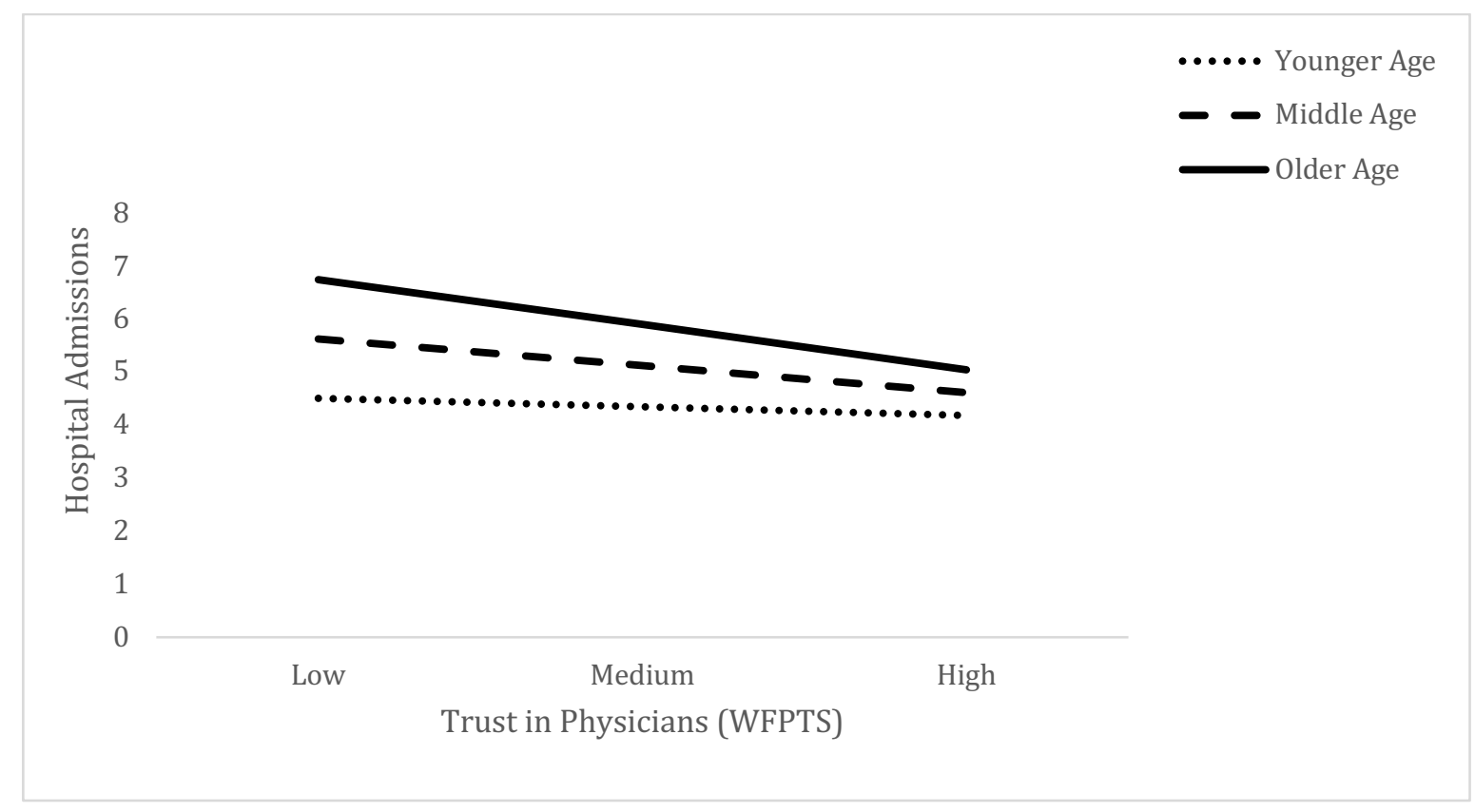

Figure 1. The moderation effect of age on trust in physicians and healthcare utilization of hospital admissions. Simple slopes test: younger age $(t=-.7738, p=.440)$, middle age $(t=$ $-3.197, p<.01)$, older age $(t=-3.748, p<.01)$. Younger age is $\sim 35$ years old, middle age is $\sim 52$ years old, and older age is $\sim 69$ years old. 


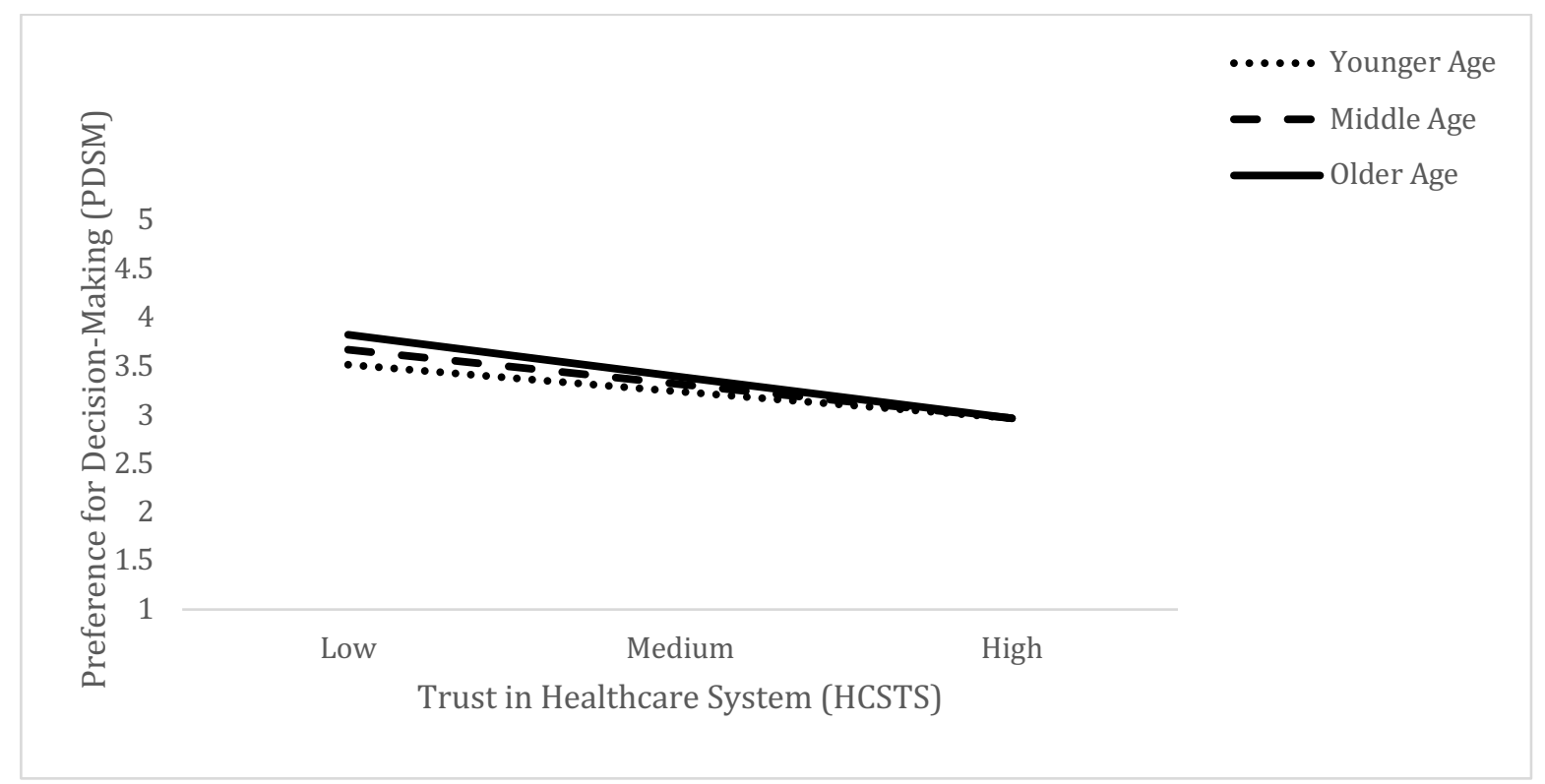

Figure 2. The moderation effect of age on trust in the healthcare system and preference for decision-making. Simple slopes test: younger age $(t=-6.273, p<.001)$, middle age $(t=-9.994, p$ $<.001)$, older age $(t=-8.555, p<.001)$. Younger age is $\sim 35$ years old, middle age is $\sim 52$ years old, and older age is $\sim 69$ years old. 


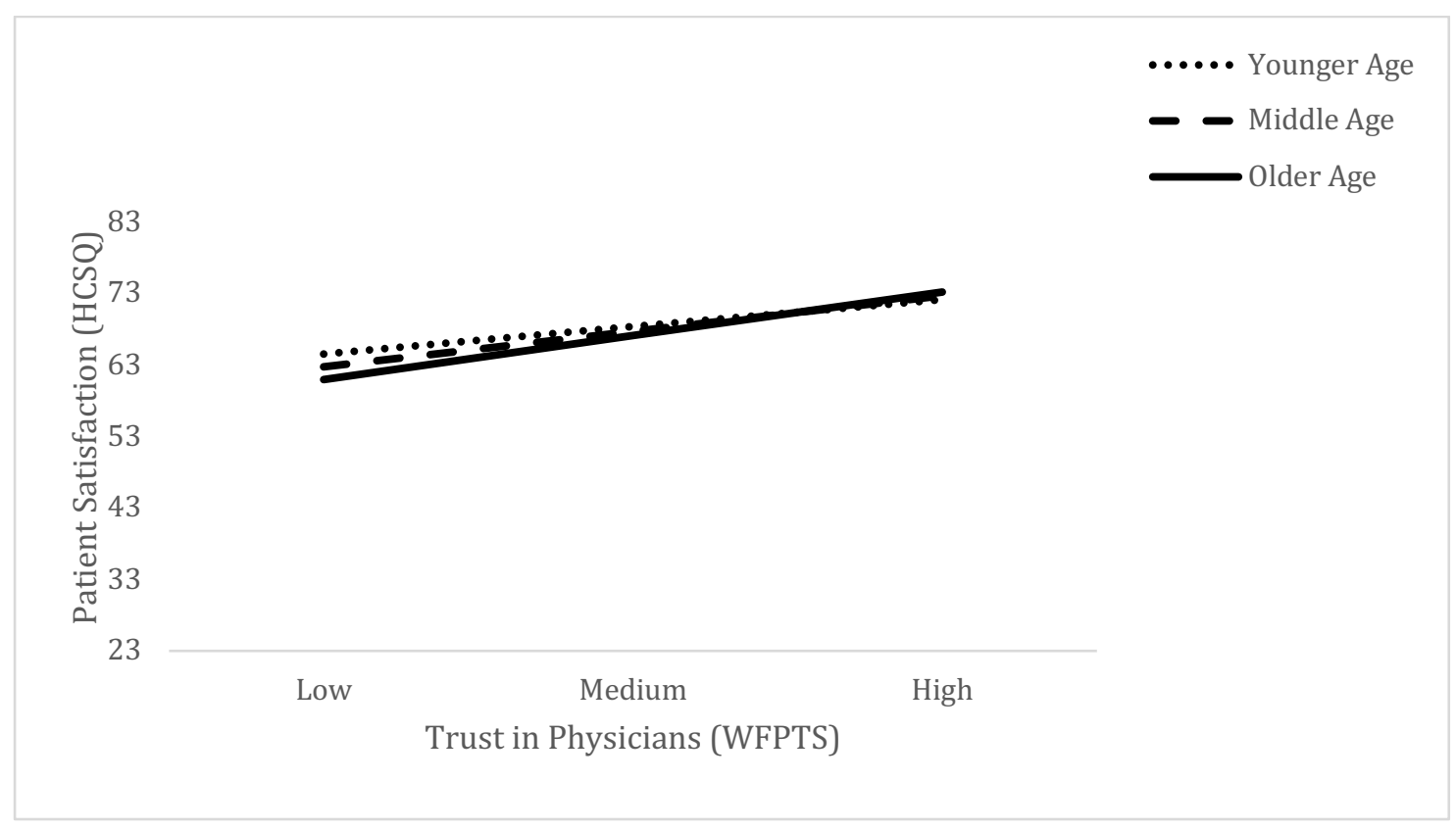

Figure 3. The moderation effect of age on trust in physicians and patient satisfaction. Simple slopes test: younger age $(t=6.971, p<.001)$, middle age $(t=13.025, p<.001)$, older age $(t=$ $12.157, p<.001)$. Younger age is $\sim 35$ years old, middle age is $\sim 52$ years old, and older age is $\sim$ 69 years old. 


\section{Appendix A}

\section{Demographic Questionnaire}

This next section will ask you general questions about yourself.

1. What is your age?

2. What is your gender?
a. Male
b. Female
c. Transgender
d. Gender nonconforming
e. Choose not to answer

3. What is your race or ethnic background? (Please choose all that apply):
a. White/Caucasian (not Hispanic)
b. Black/African American
c. Asian-American
d. Hispanic/ Latino
e. Native American (American Indian/Alaskan Native)
f. Pacific Islander
g. Other

4. Please specify if you selected Other as your answer for question \#3.

5. Please specify how many years of education you have had.

6. What is your marital status?
a. Single
b. Married
c. Live-in partner
d. Separated
e. Divorced
f. Widowed

7. What is your current job or occupation status?
a. Working full time
b. Working part time
c. Retired
d. Unemployed
e. Other

8. Please specify if you selected Other as your answer for question \#8. 
9. How many major or chronic health conditions do you have? Examples of major or chronic health conditions include hypertension, coronary heart disease (CHD), hepatitis, stroke, cancer, asthma, diabetes, arthritis, chronic obstructive pulmonary disease (COPD), and kidney disease.

10. Have you had COVID-19?
a. Yes
b. No

11. What year were you born? 


\section{Appendix B}

\section{Wake Forest Trust in Physicians Scale (Hall et al., 2001)}

Please use the below scale to indicate how much you agree with each statement.

$\begin{array}{ccccc}1 & 2 & 3 & 4 & 5 \\ \text { (strongly disagree) } & & \text { (neither agree nor disagree) } & & \text { (strongly agree) }\end{array}$

Is there a physician that you have gone to at least twice during the past 2 years? Keep them in mind while completing this measure.

1. Your doctor will do whatever it takes to get you all the care you need.

2. Sometimes your doctor cares more about what is convenient for him/her than about your medical needs.*

3. Your doctor's medical skills are not as good as they should be.*

4. Your doctor is extremely thorough and careful.

5. You completely trust your doctor's decisions about which medical treatments are best for you.

6. Your doctor is totally honest in telling you about all of the different treatment options available for your condition.

7. Your doctor only thinks about what is best for you.

8. Sometimes your doctor does not pay full attention to what you are trying to tell him/her.*

9. You have no worries about putting your life in your doctor's hands.

10. All in all, you have complete trust in your doctor.

* Item is reverse coded 


\section{Appendix C}

\section{Health Care System Trust Scale}

Please use the below scale to indicate how much you agree with each statement.

$\begin{array}{ccccc}1 & 2 & 3 & 4 & 5 \\ \text { (strongly disagree) } & & \text { (neither agree nor disagree) } & & \text { (strongly agree) }\end{array}$

1. The Health Care System does its best to make patients' health better

2. The Health Care System covers up its mistakes*

3. Patients receive high quality medical care from the Health Care System

4. The Health Care System makes too many mistakes*

5. The Health Care system puts money above patients' needs*

6. The Health Care System give excellent medical care

7. Patients get the same medical treatment from the Health Care System, no matter what the patient's race or ethnicity

8. The Health Care System lies to make money*

9. The Health Care System experiments on patients without them knowing*

* Item is reverse coded 


\section{Appendix D}

\section{PROMIS 10 Global Health Scale (Hays et al., 2010)}

Please respond to each question or statement by marking one box per row.

$\begin{array}{ccccc}1 & 2 & 3 & 4 & 5 \\ \text { Poor } & \text { Fair } & \text { Good } & \text { Very Good } & \text { Excellent }\end{array}$

1. In general, how would you say your health is?

2. In general, how would you say your quality of life is?

3. In general, how would you rate your physical health?

4. In general, how would you rate your mental health, including your mood and your ability to think?

5. In general, how would you rate your satisfaction with your social activities and your relationships?

6. In general, please rate how well you carry our your usual social activities and roles. (This includes activities at home, at work, in your community, and responsibilities as a parent, child, spouse, employee, friend, etc.).
1
2
3
4
5

Not at all A little Moderately Mostly Completely

7. To what extent are you able to carry out your everyday physical activities such as walking, climbing stairs, carrying groceries, or moving a chair?
1
2
3
4
5
Always
Often
Sometimes
Rarely
Never

8. How often have you been bothered by emotional problems such as feeling anxious, depressed or irritable?
1
2
3
4
5
Very Severe Severe $\quad$ Moderately $\quad$ Mild

9. How would you rate your fatigue on average?

10. How would you rate your pain on average? 


\section{Appendix E}

\section{Utilization of Healthcare Services Measures (Short et al., 2010)}

Please recall the total number of doctors' visits you have had within the year prior to March 1, 2020.

\section{$\begin{array}{llllllllll}1 & 2 & 3 & 4 & 5 & 6 & 7 & 8 & 9 & 10+\end{array}$}

Please recall the total number of emergency room visits you have had within the year prior to March 1, 2020.

\section{$\begin{array}{llllllllll}1 & 2 & 3 & 4 & 5 & 6 & 7 & 8 & 9 & 10+\end{array}$}

Please recall the total number of hospital admissions you have had within the year prior to March $1,2020$. 


\section{Appendix F}

\section{Problem-Solving Decision-Making Scale (Deber, Kraetschmer, \& Irvine, 1996)}

\section{Scenario A: Morbidity Vignette}

Suppose you often experience a burning sensation when you go to the bathroom. You usually have to push to begin to urinate and sometimes dribbling occurs after urination.

\begin{tabular}{|c|c|c|c|c|c|}
\hline & $\begin{array}{l}\text { Doctor } \\
\text { alone }\end{array}$ & $\begin{array}{l}\text { Mostly } \\
\text { the } \\
\text { doctor }\end{array}$ & $\begin{array}{l}\text { Doctor } \\
\text { and you } \\
\text { equally }\end{array}$ & $\begin{array}{c}\text { Mostly } \\
\text { you }\end{array}$ & $\begin{array}{l}\text { You } \\
\text { alone }\end{array}$ \\
\hline $\begin{array}{l}\text { Diagnosis: Who should determine } \\
\text { (diagnose) what the likely causes of } \\
\text { your symptoms are? }\end{array}$ & 1 & 2 & 3 & 4 & 5 \\
\hline $\begin{array}{l}\text { Options: Who should determine what } \\
\text { the treatment options are? }\end{array}$ & 1 & 2 & 3 & 4 & 5 \\
\hline $\begin{array}{l}\text { Risks and Benefits: Who should } \\
\text { determine what the risks and benefits } \\
\text { for each treatment option are? }\end{array}$ & 1 & 2 & 3 & 4 & 5 \\
\hline $\begin{array}{l}\text { Probability: Who should determine } \\
\text { how likely each of these risks and } \\
\text { benefits are to happen? }\end{array}$ & 1 & 2 & 3 & 4 & 5 \\
\hline $\begin{array}{l}\text { Utility: Given the risks and benefits } \\
\text { of these possible treatments, who } \\
\text { should decide how acceptable those } \\
\text { risks and benefits are for you? }\end{array}$ & 1 & 2 & 3 & 4 & 5 \\
\hline $\begin{array}{l}\text { What is Done: Given all the } \\
\text { information about risks and benefits } \\
\text { of the possible treatments, who should } \\
\text { decide what treatment option should } \\
\text { be selected? }\end{array}$ & 1 & 2 & 3 & 4 & 5 \\
\hline
\end{tabular}

Scenario B: Mortality Vignette

Suppose you had mild chest pains for three days and decided that you should visit your doctor about this.

\begin{tabular}{|c|c|c|c|c|}
\hline $\begin{array}{l}\text { Doctor } \\
\text { alone }\end{array}$ & $\begin{array}{l}\text { Mostly } \\
\text { the } \\
\text { doctor }\end{array}$ & $\begin{array}{c}\text { Doctor } \\
\text { and you } \\
\text { equally }\end{array}$ & $\begin{array}{c}\text { Mostly } \\
\text { you }\end{array}$ & $\begin{array}{l}\text { You } \\
\text { alone }\end{array}$ \\
\hline
\end{tabular}


Diagnosis: Who should determine (diagnose) what the likely causes of your symptoms are?

Options: Who should determine what the treatment options are?

Risks and Benefits: Who should determine what the risks and benefits for each treatment option are?

Probability: Who should determine how likely each of these risks and benefits are to happen?

Utility: Given the risks and benefits of these possible treatments, who should decide how acceptable those risks and benefits are for you?

What is Done: Given all the information about risks and benefits of the possible treatments, who should decide what treatment option should be selected?

\section{1}

1

\section{2}

2
1

1

1

2

2

2

1
2

3

4

5

\section{Scenario C: Quality of Life Vignette}

Suppose you and your partner have been trying for pregnancy but have been unsuccessful for more than a year.

\begin{tabular}{lccccc}
\hline & $\begin{array}{c}\text { Doctor } \\
\text { alone }\end{array}$ & $\begin{array}{c}\text { Mostly } \\
\text { the } \\
\text { doctor }\end{array}$ & $\begin{array}{c}\text { Doctor } \\
\text { and you } \\
\text { equally }\end{array}$ & $\begin{array}{c}\text { Mostly } \\
\text { you }\end{array}$ & $\begin{array}{c}\text { You } \\
\text { alone }\end{array}$ \\
\hline $\begin{array}{l}\text { Diagnosis: Who should determine } \\
\text { (diagnose) what the likely causes of } \\
\text { your symptoms are? }\end{array}$ & 1 & 2 & 3 & 4 & 5 \\
$\begin{array}{l}\text { Options: Who should determine what } \\
\text { the treatment options are? }\end{array}$ & 1 & 2 & 3 & 4 & 5 \\
$\begin{array}{l}\text { Risks and Benefits: Who should } \\
\text { determine what the risks and benefits } \\
\text { for each treatment option are? }\end{array}$ & 1 & 2 & 3 & 4 & 5
\end{tabular}


Probability: Who should determine how likely each of these risks and benefits are to happen?

Utility: Given the risks and benefits of these possible treatments, who should decide how acceptable those risks and benefits are for you?

What is Done: Given all the information about risks and benefits of the possible treatments, who should decide what treatment option should be selected?
1

2

3

4 5

1 2

3

4 5

1 2 3 4 5 
Appendix G

\section{Adherence Measure}

How often do you follow what your physician prescribes for you?

$\begin{array}{llccc}1 & 2 & 3 & 4 & 5 \\ \text { Never } & \text { Rarely } & \text { Some of the time } & \text { Most of the time } & \text { Always }\end{array}$




\section{Appendix $\mathrm{H}$}

\section{Health Care Satisfaction Questionnaire (Gagnon et al., 2006)}

Please use the below scale to indicate how much you agree with each statement.

$\begin{array}{cccc}1 & 2 & 3 & 4 \\ \text { Not at all } & \text { Somewhat } & \text { Very Much } & \text { Extremely }\end{array}$

1. Do you feel that you can trust the professionals?

2. Do you feel that the professionals are courteous?

3. Do you feel that the professionals respect your privacy?

4. Do you feel that the professionals you met seem competent?

5 . Do you feel that the professionals treat your information confidentially?

6. Do you feel that you receive honest answers to your questions?

7. Do you feel that the same professional looks after you each time?

8. Do you feel that the professionals treat you with respect?

9. Do you feel that the professionals show a sense of responsibility toward you?

10. Do you feel that the professionals really understand your needs?

11. Do you feel that the professionals you met take your problem seriously?

12. Do you feel that the professionals talk to you in words you can understand?

13. Do you feel that the professionals encourage you to get support from your family and friends?

14. Do you feel that the professionals tell you about the different choices you have?

15. Do you feel that the professionals give you advice regarding how to prevent the problem from recurring?

16. Do you feel that the professionals give you all the information you need about where to go, what to do, and what not to do?

17. Do you feel that the professionals inform you about the available services?

18. Do you feel that the professionals take your lifestyle into account?

19. Do you feel that the appointments you make with the professionals are obtained quickly?

20. Do you feel that you don't have to go through too many steps when you want to contact a professional?

21. Do you feel that you didn't have go through too many steps when you wanted to get help?

22. Do you feel that the professionals take the necessary time to take care of you?

23. Do you feel that the professionals are accessible at times that are convenient for you? 